\title{
ChaRACTERISTICS OF Hydrothermally TREATED BEESWAX AMBER
}

Yamei Wang, Yan Li, Fen Liu, Fangli Liu, and Quanli Chen

The gemological characteristics of natural milky "beeswax" amber are compared with those enhanced by hydrothermal treatment. A layer of variable thickness of yellowish white or greenish yellow hydrothermally treated skin is generated below the natural, weathered skin of rough amber after this treatment. Different-sized pores and newly grown brown or yellowish white crust-like skin appear locally on the surface of the rough amber. Finished products show a white residue of hydrothermally treated spots. The treated beeswax displays abundant gas-liquid inclusions with small and flattened gas bubbles or disk-shaped bubbles accompanied by tiny straininduced fractures. The gas bubbles are uneven in size and densely distributed, forming a cloud-like effect. A series of comprehensive tests are required to identify hydrothermally treated beeswax amber (HT amber).

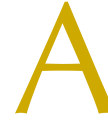
mber is an organic gem, formed tens of millions of years ago when sap from ancient trees hardened and fossilized. Scientists, gemologists, and collectors treasure amber that contains suspended insects or assorted plant fragments, creating a fascinating time capsule (Ross, 2010). Amber has become increasingly popular in the jewelry trade. It is usually translucent to opaque, and its opacity is caused by the reflection and scattering of incident light by an abundance of internal tiny bubbles. "Beeswax," a term commonly used in the Chinese gem trade, refers to amber that is semi-translucent to opaque with greasy luster. Beeswax accounts for about $60 \%$ of natural amber production globally. Due to the saying "Millennium amber, million years beeswax" in the Chinese gem market, many Chinese consumers mistakenly believe that beeswax takes much longer to form than amber. This misimpression has driven demand for beeswax and significantly raised its price.

Among beeswax, the "chicken-fat" yellow variety is highly desired in China for its vivid color, but limited in global production. It is worth noting that in the international rough amber trade, transparent and opaque materials are usually mixed together for sale, just as they are mixed together in nature. There is usually a layer of weathered skin on the surface of

See end of article for About the Authors and Acknowledgments.

Gems \& Gemology, Vol. 55, No. 3, pp. 370-387,

http://dx.doi.org/10.5741/GEMS.55.3.370

(C) 2019 Gemological Institute of America both transparent and opaque rough amber, making it impossible to choose them individually by hand under normal lighting. There is no price difference between the two. Quality is judged according to weight, size, shape, and impurities.

Due to the popularity of beeswax in the Chinese market, however, amber processing enterprises have preferred to purchase and store rough beeswax materials, artificially driving up the price of the rough ma-

\section{In Brief}

- Hydrothermally treated amber is produced by heating the material in an aqueous solution with some catalyst to convert it from transparent to opaque.

- Hydrothermally treated amber shows yellowish white or greenish yellow hydrothermally treated skin below natural weathered skin. Various-sized pores and newly grown cracks or brown crust-like skin are developed on the surface of treated rough amber, and a residue of white spots is left in treated products.

- Hydrothermally treated amber displays abundant gasliquid inclusions with small and flattened gas bubbles or disk-shaped bubbles accompanied by tiny straininduced fractures. The bubbles are of different sizes and densely distributed, forming a cloud-like effect.

terial. Numerous researchers (e.g., Brody et al., 2001; Zhang, 2003; Zhang, 2006; Feist et al., 2007; Abduriyim et al., 2009; Ross, 2010; Wang et al., 2010, 2014) have investigated the methods to enhance the quality of amber. Many techniques have been at- 

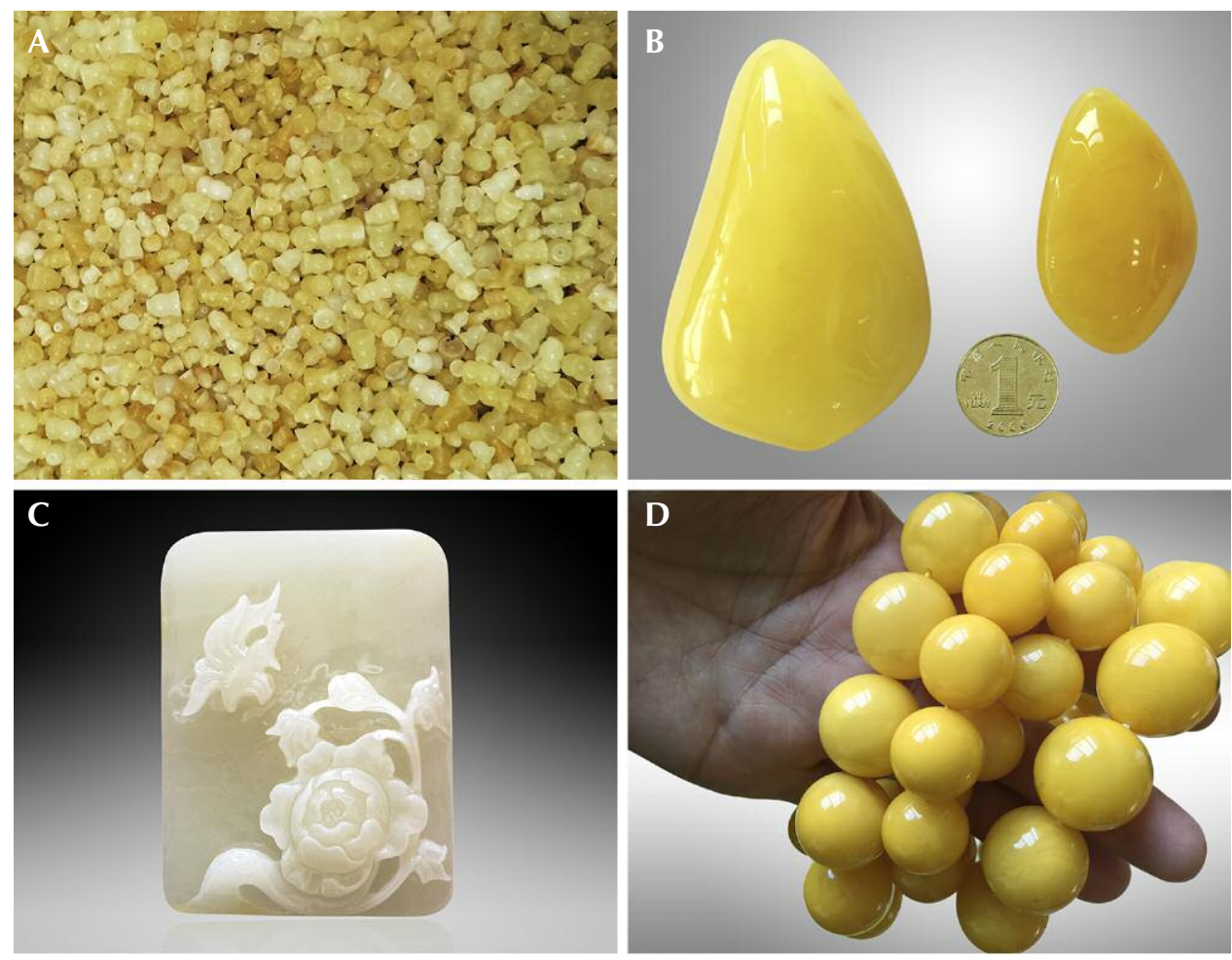

Figure 1. Various commercial HT amber products. A: calabash beads (751 g total). B: light yellow and yellow beeswax drop-shaped pendants. C: carved pendant (white HT beeswax). D: roasted "chicken-fat" yellow beads. E and F: goodquality and poor-quality necklaces of roasted HT amber. Photos by
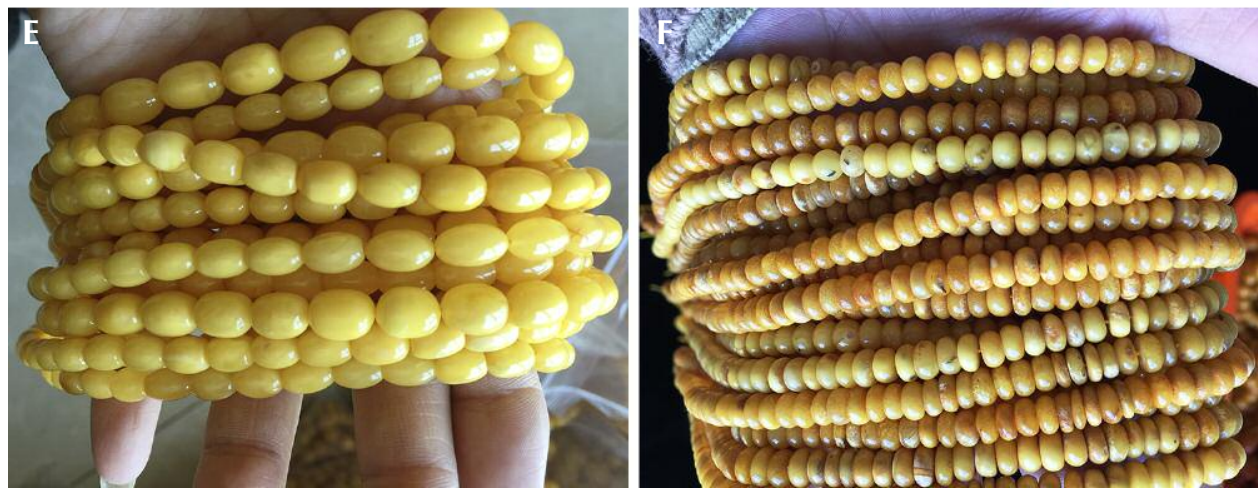
Yamei Wang

tempted to improve the color of beeswax amber, such as heat treatment. Driven by profit, foreign rough suppliers have converted ordinary and low-quality transparent amber to opaque beeswax via hydrothermal treatment to cater to Chinese consumers.

In recent years, Chinese amber manufacturers have gradually mastered hydrothermal treatment through continuous exploration and technology transfer. This is a novel method to optimize the appearance of semi-translucent to opaque amber by heating it with controlled temperature and pressure in a furnace in aqueous solution and inert atmosphere. Submicron- and micron-sized gas bubbles are able to migrate into the amber during this process. As a result, the treated amber exhibits a uniform and compact appearance, and these commercial products are commonly known as hydrothermally treated or "HT" amber. This treatment expands the availability of amber products but leads to identification challenges.

The quality of HT amber varies, since manufacturers employ a range of technologies and rough materials. This method is generally applicable to rough amber materials, semi-finished products, and finished products. Common HT amber products include beads (figure 1A) and some pendants (figure 1, B-C). The majority of HT amber beads are used to produce "roasted old beeswax" (figure 1, D-F; box A details this and other common terms in the Chinese amber trade). Hydrothermal treatment followed by heat treatment can produce beeswax with a "chicken-fat yellow" color (figure 1D). 


\section{Box A: Terminology Used in the Chinese Amber Market}

Beeswax: a common term in the Chinese gem trade, referring to semi-translucent to opaque amber that has an opalescent, milky appearance with greasy luster (figures A-1C and A-2A).

Chicken-fat yellow beeswax: the most desired beeswax variety, possessing a vivid yellow color (figure A-1D).

Gold-twisted honey amber: amber with semi-transparent and semi-opaque internal features (figure A-1B).

Golden amber: golden transparent amber (figure A-1A).

HT: hydrothermally treated, as in HT amber, beeswax, or copal resin.

Roasted HT beeswax: hydrothermally treated beeswax that subsequently undergoes heat treatment to enhance its color (figure A-2C).

Roasted old beeswax: white or light yellow beeswax that is heat-treated to enhance the color to a dark or saturated yellow (figure A-2B).

Weathered skin: a rough layer developed on the surface of amber after tens of millions of years of exposure to heat and pressure. Due to density variance between different resin layers, evaporation and volatilization occurred together with oxidation, which caused the surface layer to shrink, crack, and form irregular linear features.
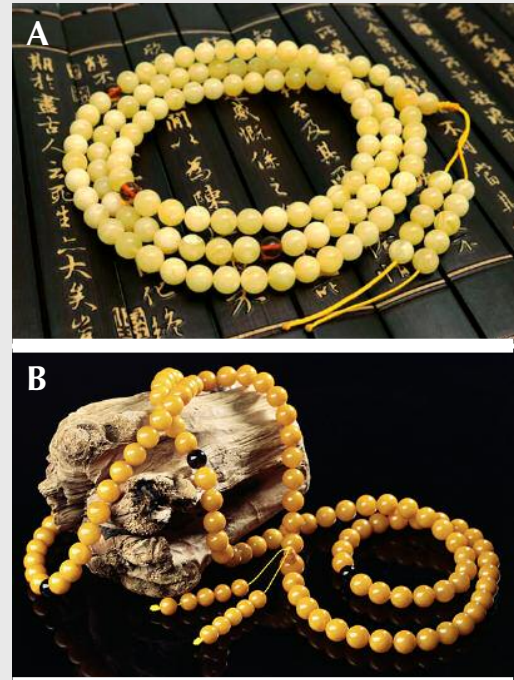

Figure A-2. Images of (A) a natural beeswax strand, (B) a roasted old beeswax strand, and $(C)$ a roasted HT beeswax strand. Photos by Yamei Wang.

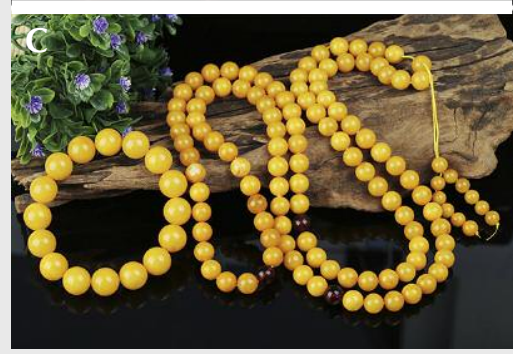

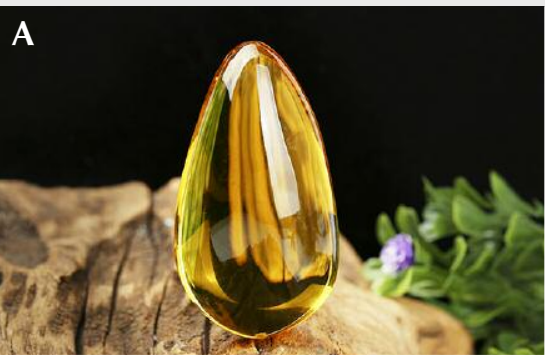
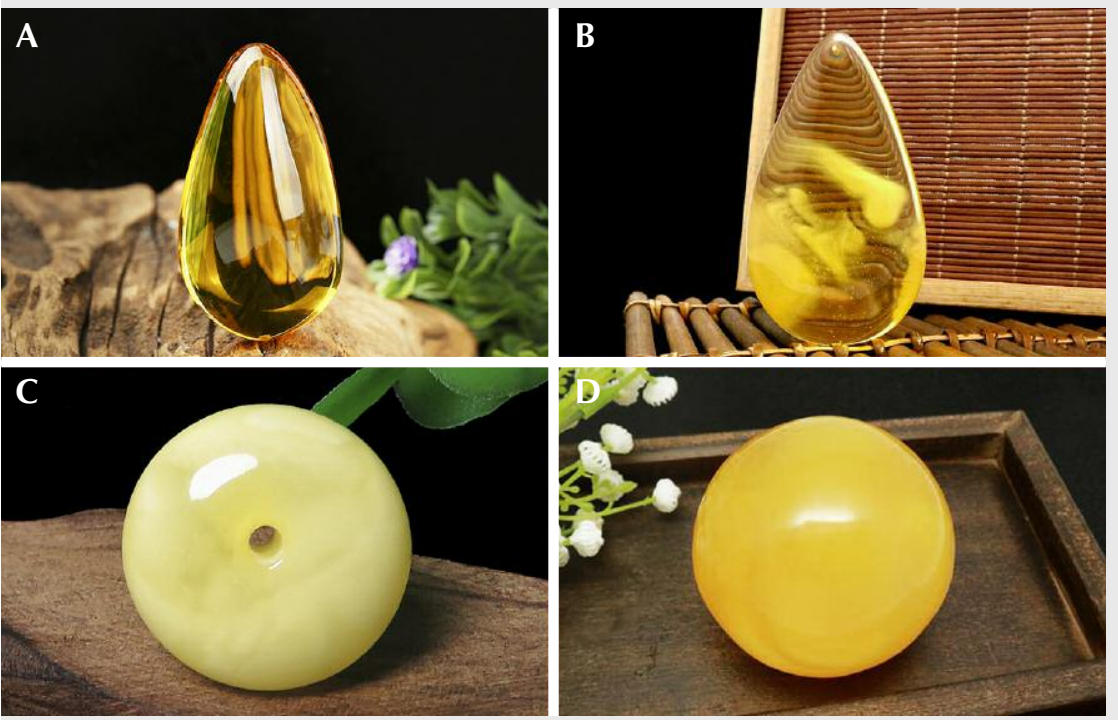

Figure A-1. Images of (A) golden amber, (B) gold-twisted honey amber, (C) beeswax, and (D) chicken-fat yellow beeswax. Photos by Yamei Wang.
Through experiments, investigation of manufacturing processes, and extensive research and identification practice, the authors have developed a method to identify HT amber (Wang et al., 2010, $2014,2017)$. In the present work, the authors studied the inclusions and IR spectra of the specimens before and after hydrothermal treatment, providing valuable information regarding the formation mechanisms and identification characteristics of HT amber. 

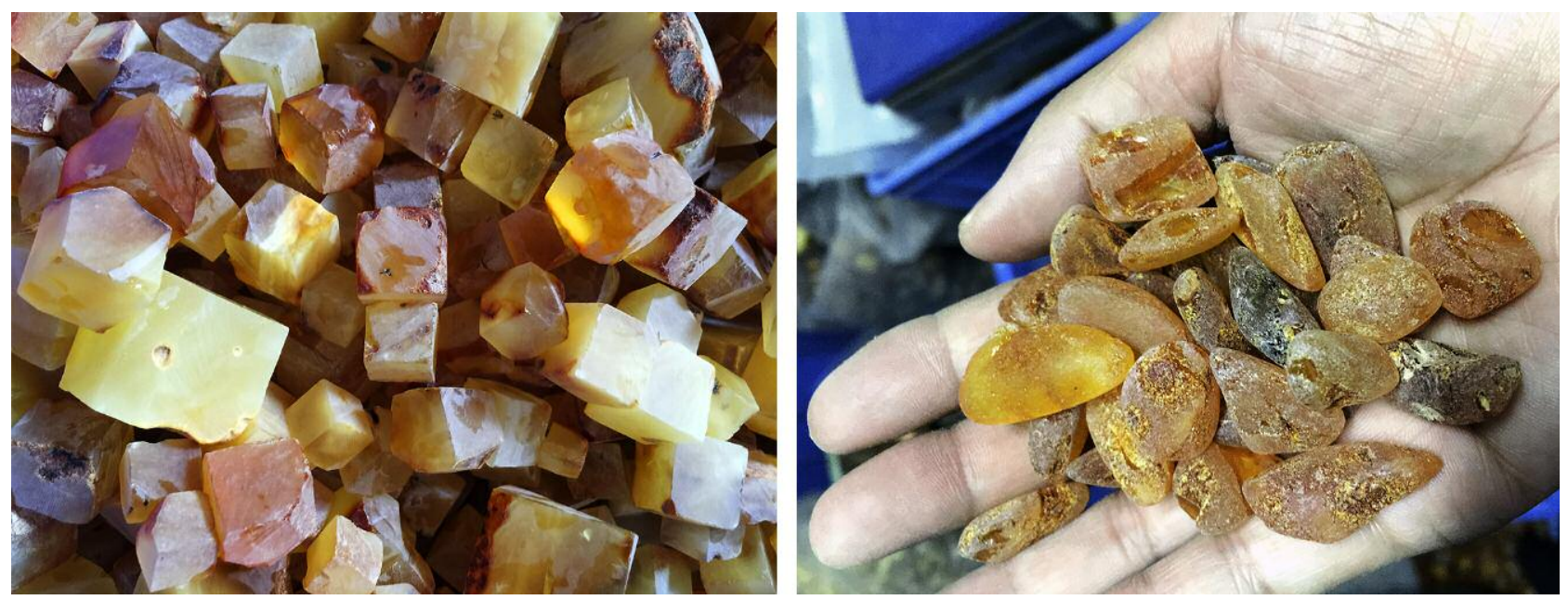

Figure 2. Rough amber materials before hydrothermal treatment, photographed at manufacturing facilities. Gold-twisted honey amber rough is shown on the left, transparent golden amber rough on the right. Photos by Yamei Wang.

\section{MATERIALS AND METHODS}

Specimens. The rough amber for hydrothermal treatment experiments in this study was sourced from Kaliningrad, Russia. Beeswax is a unique variety of Baltic amber, and amber rough material for HT is mostly selected from Baltic amber. (The use of Colombian copal resin for HT copal is also found in the market; see the Results section under "Microscopic Characteristics of Hydrothermally Treated Copal Resin.") Two types of commonly used rough materials for hydrothermal treatment were chosen as samples: gold-twisted honey amber (partially transparent and partially opaque) and transparent golden amber (both are shown in figure 2). Three representative specimens, labeled as I, II, and III, were used for the hydrothermal treatment experiment in this study (gemological characteristics of chosen specimens can be found in table 1 and figure 4). Sample III was further heat-treated to mimic old beeswax, since in the trade HT amber is often heated to form roasted old beeswax.

Some rough amber pieces (with and without weathered skin) presented in the Results and Discussion sections were typical HT specimens collected by the authors from Chinese manufacturing facilities. The others were client submissions previously examined at the China University of Geosciences gem testing center in Guangzhou, China. All of these samples, studied by the authors over many years, were used to show identification features of HT amber.
The HT amber finished products and copal resin beads were client submissions previously examined at the gem testing center in Guangzhou. These are typical examples of commercial HT amber and HT copal resin to mimic natural beeswax in the trade. Observations of these products are also presented in this study.

Hydrothermal Treatment Experiment. Hydrothermal treatment aims to introduce an abundance of tiny bubbles (nano- and micron-sized) into the amber in an aqueous solution with some catalyst. Doing so optimizes the appearance of amber by converting it from transparent to opaque to mimic beeswax. Hydrothermal treatment is carried out in a pressure autoclave by controlling the temperature and pressure and selecting an inert atmosphere (figure 3), similar to the pressure furnace established for amber heat treatment (Wang et al., 2014).

Optical Microscopy and Scanning Electron Microscopy. Morphological analysis was carried out via optical microscopy (Olympus BX 60) and scanning electron microscopy (FEI Inspector-F) with an electron beam of $20 \mathrm{kV}$. SEM was conducted to assess the morphology of the bubbles in the amber with gold coating at room temperature.

Fourier-Transform Infrared Spectrometry. Three amber samples before and after hydrothermal treat- 


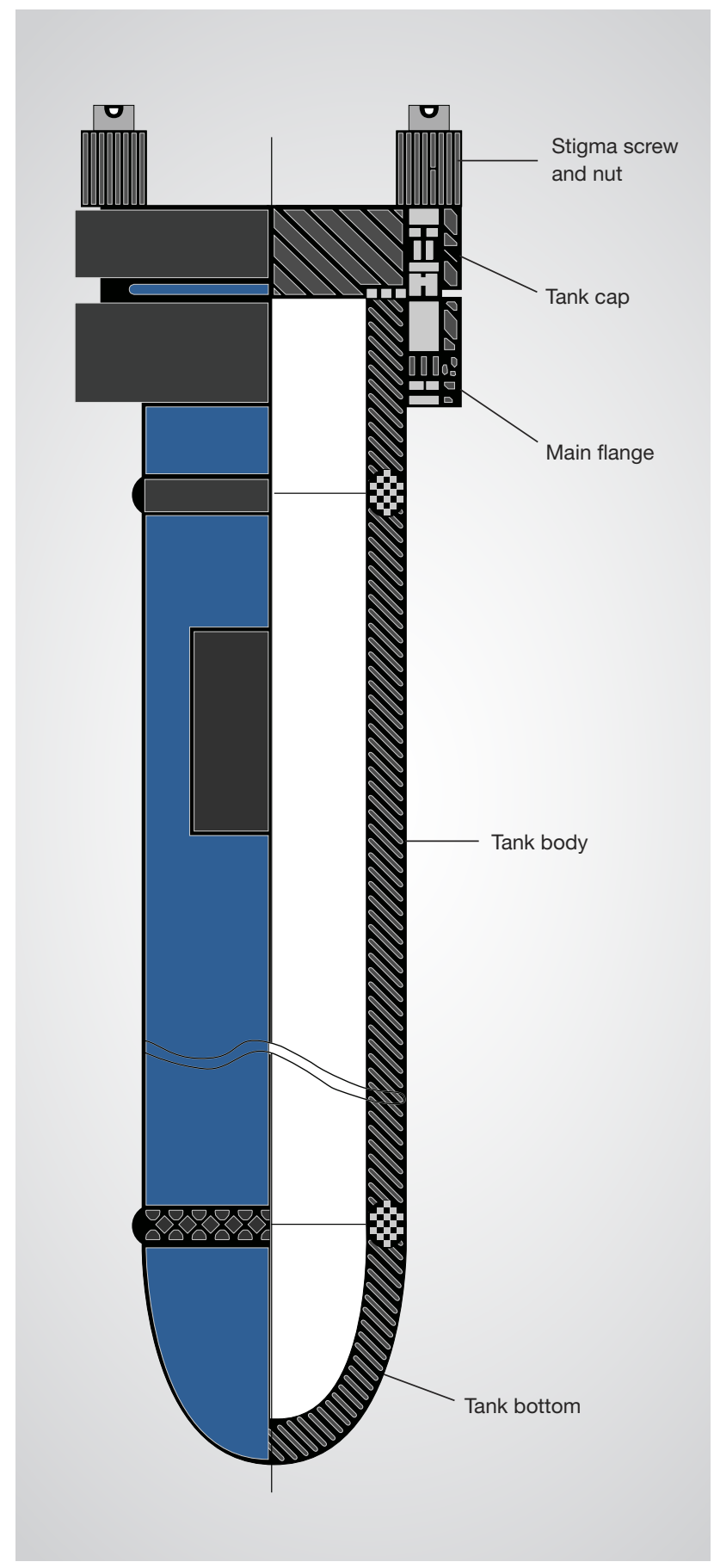

Figure 3. Diagram of the pressure furnace used for hydrothermal treatment.

ment were measured using a Bruker Tensor-27 Fourier transform infrared (FTIR) spectrometer to check the variations among the functional groups of samples. FTIR was used to reflectively scan each sample 32 times in the range of approximately 4000 $400 \mathrm{~cm}^{-1}$.

\section{RESULTS}

Gemological Characteristics of Rough Amber Before Hydrothermal Treatment. Three semi-finished amber samples were chosen and polished as much as possible to remove their weathered skin before hydrothermal treatment (figure 4). The gemological characteristics of these rough amber specimens (samples I, II, and III) before hydrothermal treatment are listed in table 1. Sample III was heated after hydrothermal treatment.

Characteristics of Rough Amber Material After Hydrothermal Treatment. In our experiment, the three samples changed from transparent to translucent or opaque after hydrothermal treatment, achieving the expectation of treatment (see the characteristics in table 2). The color of the golden amber (samples I and II) became darker, while the gold-twisted honey amber (sample III) became white. All three developed a layer of khaki-colored, hydrothermally treated skin or white hydrothermally treated spots (figure 5, AF). However, the samples' refractive index and fluorescence intensity did not change much.

There was no significant difference in the infrared absorption spectra of the three samples before and after hydrothermal treatment (figure 5G). Spectra show that the characteristics of the aliphatic skeleton structure consist of absorption peaks caused by the stretching vibration of $\mathrm{C}-\mathrm{H}$ saturated in the range of approximately 3000 to $2800 \mathrm{~cm}^{-1}$ (Wang et al., 2010). The corresponding absorption peaks at 1457 and $1378 \mathrm{~cm}^{-1}$ are attributed to $\delta\left(\mathrm{CH}_{2}-\mathrm{CH}_{3}\right)$ bending vibration and carbonyl stretching vibration absorption peaks ranging from 1695 to $1736 \mathrm{~cm}^{-1}$. In addition, the samples have a wide absorption shoulder (Baltic shoulder) in the range of 1261 to $1164 \mathrm{~cm}^{-1}$, which is attributed to the C-O stretching vibration. This is an unusual peak shape for Baltic amber.

The effect of hydrothermal treatment can vary depending on the starting materials. The gold-twisted honey amber (translucent, semi-beeswax-like) achieves the best appearance after treatment, while golden amber performs the worst. An important value factor of beeswax is "waxiness," a term that describes whether the materials look and feel compact and uniform. Compact and uniform high-quality HT amber only accounts for one-third of the material treated. Waxiness is related to the number and size of the gas bubbles inside the amber. Larger bubbles generate more surface area to diffuse light, but they also make the texture of beeswax rough. 

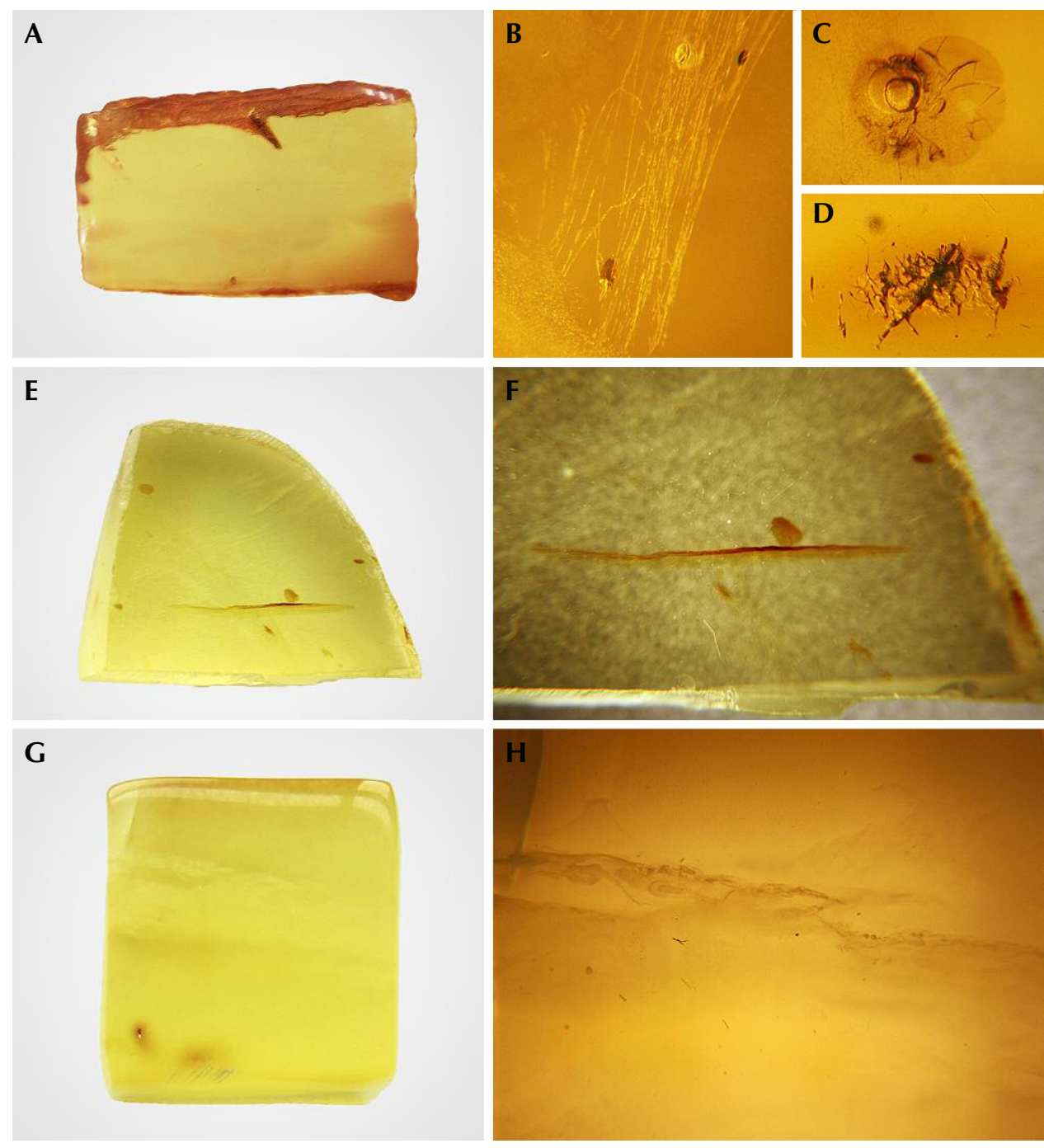

Figure 4. Gemological characteristics of rough amber specimens before hydrothermal treatment. A: sample I (golden amber, $10.20 \mathrm{~g}$ ). $B$ : filament and flow striation in sample I (field of view $11 \mathrm{~mm}$ ). $C$ : gas-liquid inclusions in sample I (field of view $5.5 \mathrm{~mm}$ ). $D$ : internal impurities in sample I (field of view 7 $\mathrm{mm})$. E: sample II (golden amber, $2.24 \mathrm{~g}$ ). F: internal red crack in sample II (field of view $22 \mathrm{~mm})$. G: sample III (gold-twisted honey amber, $2.39 \mathrm{~g}$ ). H: translucent, semi wax-like inclusions in sample III (field of view $16 \mathrm{~mm}$ ). Photos by Yamei Wang.
Therefore, high-quality beeswax needs to have a large amount of small gas bubbles.

Visiting the factory, author WYM also noticed features that developed on HT rough amber. A new layer of greenish yellow, yellowish white HT skin oc- curred below the natural weathered skin of most HT amber rough materials (figure 6, A-B). This HT layer, which formed when a large amount of tiny gas bubbles quickly gathered in the shallow surface, had a relatively high porosity (figure 6A). A gradual transi-

TABLE 1. Gemological characteristics of the rough amber samples.

\begin{tabular}{|c|c|c|c|c|c|c|c|}
\hline Sample no. & Weight (g) & Category & Origin & Color & Transparency & $\begin{array}{l}\text { UV } \\
\text { fluorescence (LW) }\end{array}$ & Internal characteristics \\
\hline I & 10.20 & Golden amber & Russia & Golden yellow & Transparent & $\begin{array}{l}\text { Medium } \\
\text { yellowish white }\end{array}$ & $\begin{array}{l}\text { Internally clean, partial flow pattern, } \\
\text { gas-liquid inclusions, filaments, and } \\
\text { internal impurities }\end{array}$ \\
\hline II & 2.24 & Golden amber & Russia & Bright yellow & Transparent & $\begin{array}{l}\text { Strong yellowish } \\
\text { white }\end{array}$ & $\begin{array}{l}\text { Internally clean, with only a small } \\
\text { red crack }\end{array}$ \\
\hline III & 2.39 & $\begin{array}{l}\text { Gold-twisted } \\
\text { honey }\end{array}$ & Ukraine & Yellow & $\begin{array}{l}\text { Translucent and } \\
\text { semi wax-like }\end{array}$ & $\begin{array}{l}\text { Strong yellowish } \\
\text { white }\end{array}$ & $\begin{array}{l}\text { Transparent and opaque beeswax } \\
\text { twisted together, as well as various } \\
\text { sizes of bubbles }\end{array}$ \\
\hline
\end{tabular}



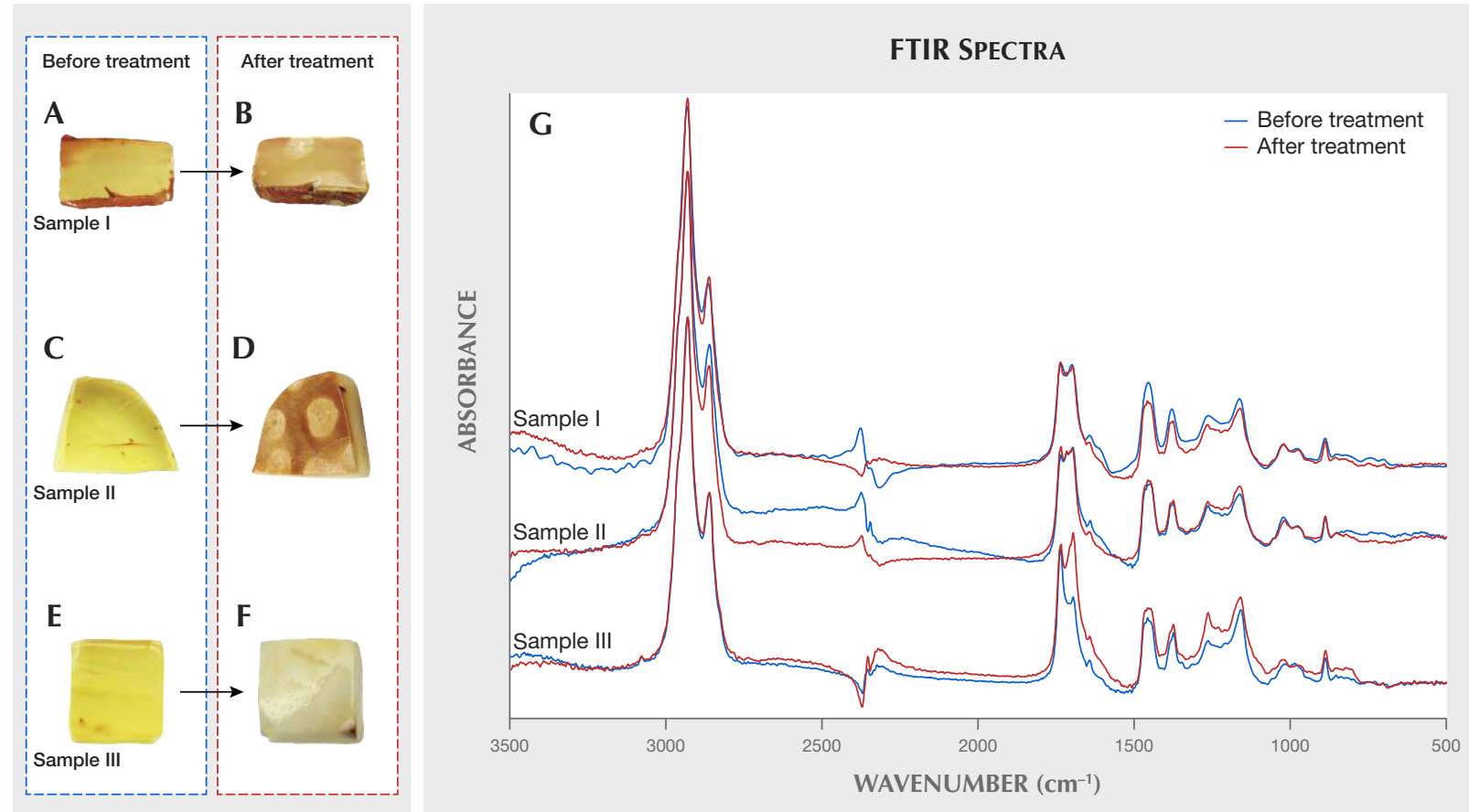

Figure 5. Variations in the appearance of amber samples before and after hydrothermal treatment: samples I (A and B), II (C and D), and III (E and F). G: infrared absorbance before and after hydrothermal treatment. Note that there was no weight change after hydrothermal treatment. Photos by Yamei Wang.

tion was observed (figure 6, C-D) from larger bubbles to smaller bubbles with increasing depth (figure 6, EF). No such size change was observed within the white HT skin.

A circular weathered disk often forms around HT spots with various sizes, a feature that can be used to distinguish treated beeswax (figure 7, A-B). This disk can penetrate the amber and remain on the surface after polishing (figure 7, C-D). It was speculated that the weathered disk around HT spots formed after prolonged soaking in the condensation water droplets and that HT spots might be caused by vaporization of water molecules in the furnace. Some of the water vapor molecules are recondensed into

TABLE 2. Gemological characteristics of specimens before and after hydrothermal treatment.

\begin{tabular}{|c|c|c|c|c|c|c|}
\hline Sample no. & & Color & Transparency & RI & Fluorescence (LW) & Appearance \\
\hline \multirow{2}{*}{ I } & Before & Gold yellow & Transparent & 1.54 & Medium yellow & \multirow{2}{*}{$\begin{array}{l}\text { The purpose of treatment was } \\
\text { achieved, but the effect was just } \\
\text { fair. A white layer of HT skin } \\
\text { was developed (figure 5, A and } \\
\text { B). The inclusions were invisible } \\
\text { after hydrothermal treatment. }\end{array}$} \\
\hline & After & Darker yellow-brown & Semi-translucent & 1.54 & Strong yellow-white & \\
\hline \multirow{2}{*}{ II } & Before & Light yellow & Transparent & 1.54 & Strong yellow-white & \multirow{2}{*}{$\begin{array}{l}\text { A new layer of HT skin and } \\
\text { spots developed (figure } 5, \mathrm{C} \\
\text { and D). }\end{array}$} \\
\hline & After & Darker yellow-brown & Opaque & 1.54 & Strong yellow-white & \\
\hline \multirow[t]{2}{*}{ III } & Before & Yellow & $\begin{array}{c}\text { Translucent and } \\
\text { somewhat wax-like }\end{array}$ & 1.54 & Strong yellow-white & \multirow{2}{*}{$\begin{array}{l}\text { The amber changed to white } \\
\text { and showed uniform wax luster } \\
\text { after hydrothermal treatment } \\
\text { (figure } 5, \mathrm{E} \text { and F). }\end{array}$} \\
\hline & After & Yellow-white & Opaque & 1.54 & Strong yellow-white & \\
\hline
\end{tabular}



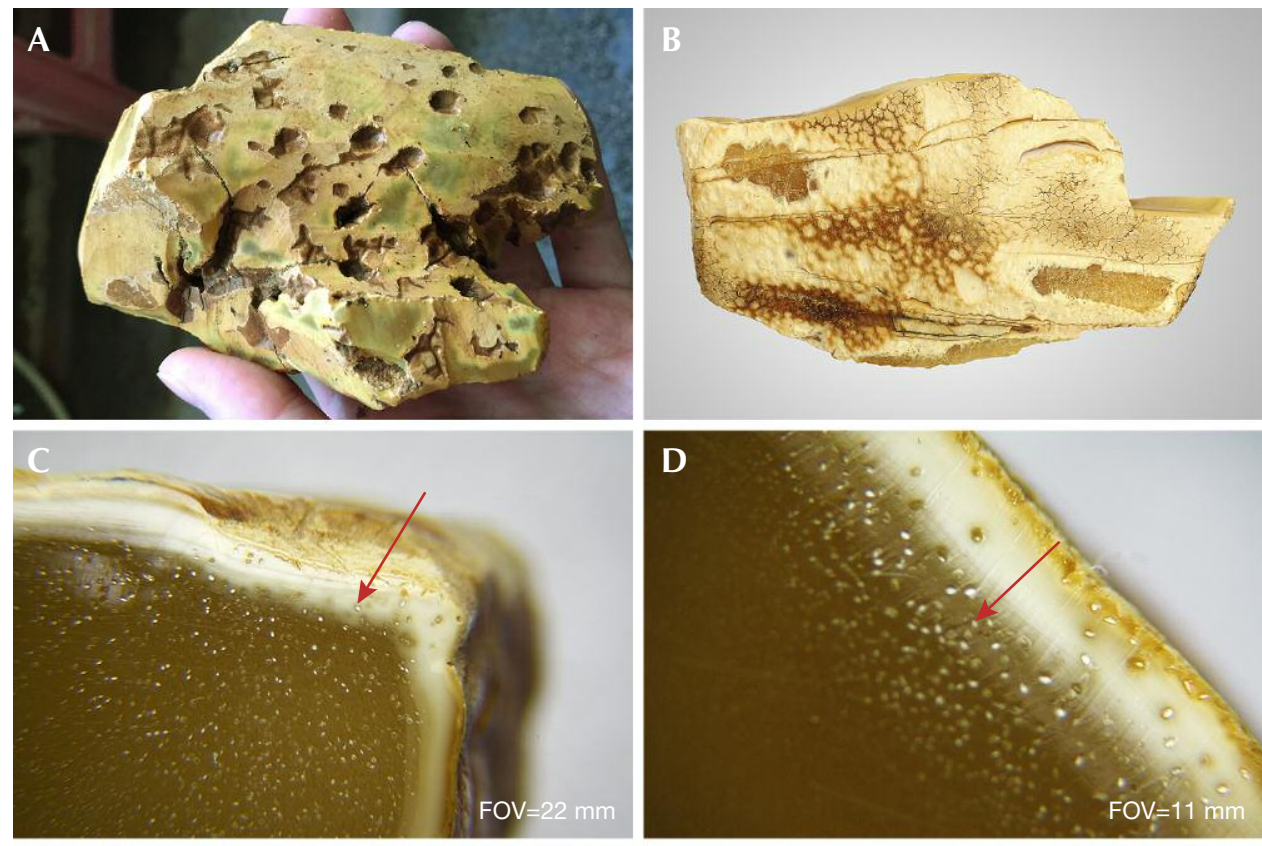

Figure 6. External and internal characteristics of HT amber rough. A: yellowish green $H T$ skin. B: yellowish white HT skin. $C$ and D: HT skin transition phenomenon. E and F: bubble stratification phenomenon. These previously examined samples were collected from manufacturing fa-
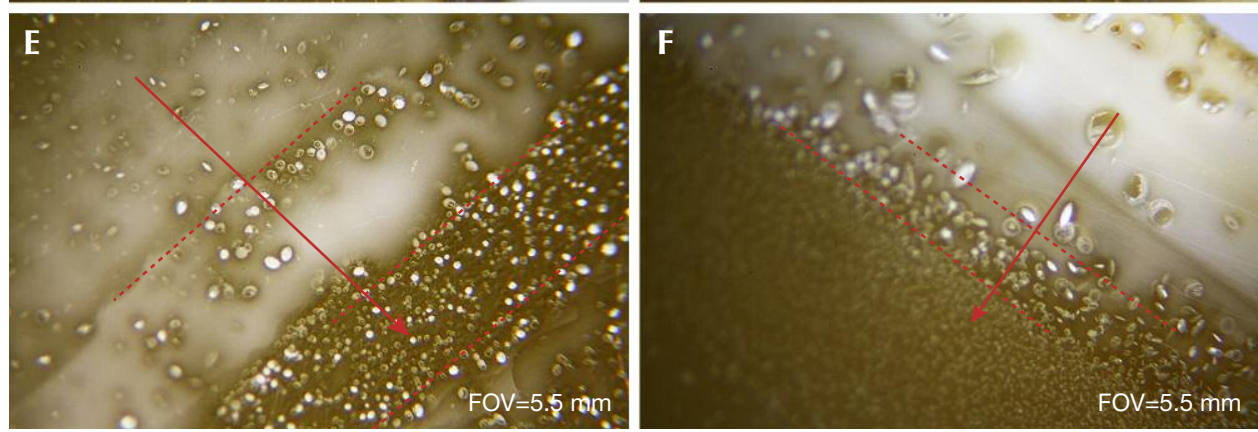
cilities. Photos by Yamei Wang.

water droplets left on the surface of HT amber (a permanent residue).

The surface of the freshly HT amber shows a "water ripple" structure (figure 8, A-B), and is often locally accompanied by a layer of yellowish white or greenish yellow HT skin with various thicknesses, or a corrugated, crust-like skin containing mostly oval pores (figure 8, C-D). Some surface areas on the HT skin are cracked, forming a crust-like texture (figure $8 \mathrm{E}$ ). In some cases, yellowish white HT skin is found below the black naturally weathered skin of rough amber (figure $8 \mathrm{~F}$ ). All these features are quite different from the weathered skin or cracks on untreated amber. The HT skin and spots are therefore diagnostic evidence of HT amber.

Microscopic Characteristics of Finished HT Amber. The appearance of HT amber is mostly uniform and waxy (figure 1, B-E) with undeveloped flow lines, sometimes with white HT spots as well as a compact structure. With magnification, one can easily detect an abundance of gas bubbles around HT spots. These bubbles lower the transparency of the amber. A larger number of smaller bubbles provides a higher-quality treated amber (figure 9, A-B). Dense, flat, or diskshaped gas bubbles or gas-liquid inclusions are commonly found in HT amber (figure 9, C-F). The size range of gas bubbles in HT amber is substantially greater than that in untreated beeswax.

HT amber retains the natural flow lines of goldtwisted honey amber. However, the flow lines appear disordered, less clear, and smoother compared to the pattern in natural beeswax, which may be attributed to the impact of later gas intervention (figure 9, G-H).

In the Chinese market, most HT beeswax materials are further heated to obtain a vivid yellow color. The surface of HT beeswax is slowly oxidized during 

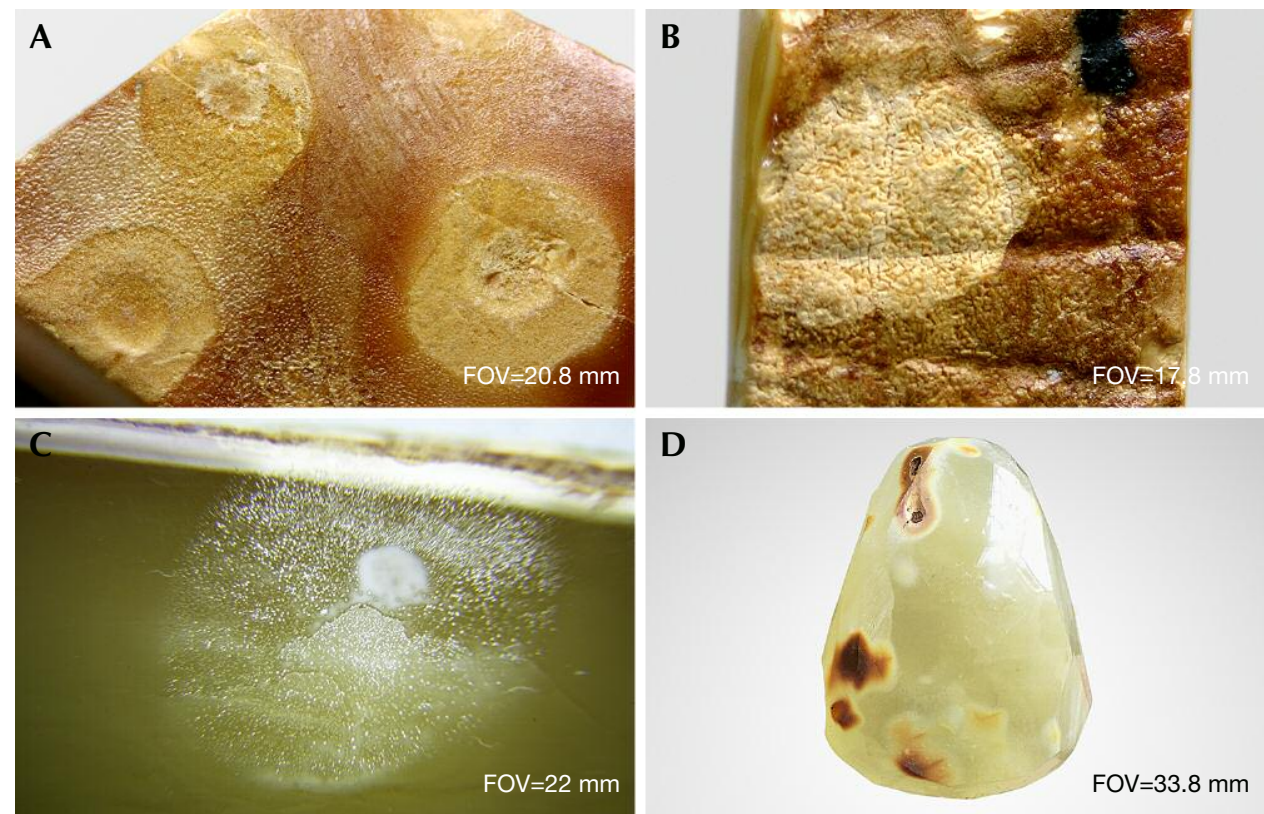

Figure 7. Features of hydrothermally treated spots. A: newly generated spots on the HT skin of sample II. B: newly generated spots on the weathered skin of sample I. C: spots penetrated the HT skin. D: spots on the polished surface. These previously examined samples were collected from amber manufacturing factories. Photos by Yamei Wang.

the heat treatment, and the color may reach chickensized and different-colored bubbles near the surface fat yellow. There is an obvious layering of differentof roasted HT amber (figure 9I). There is no color dif-
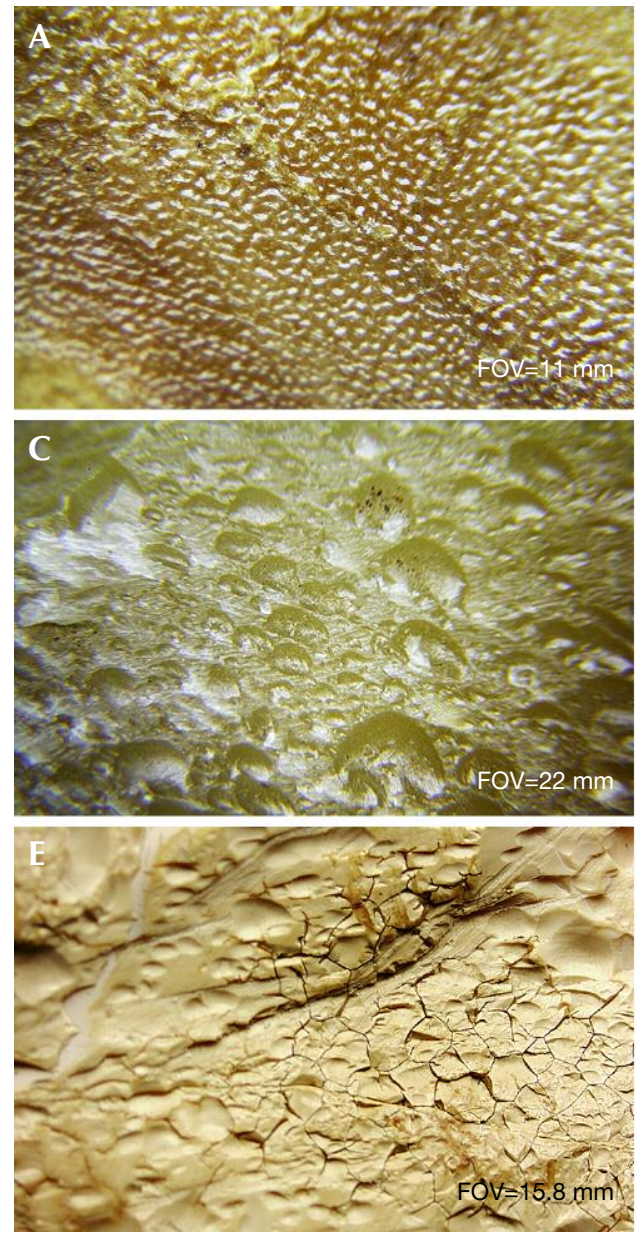
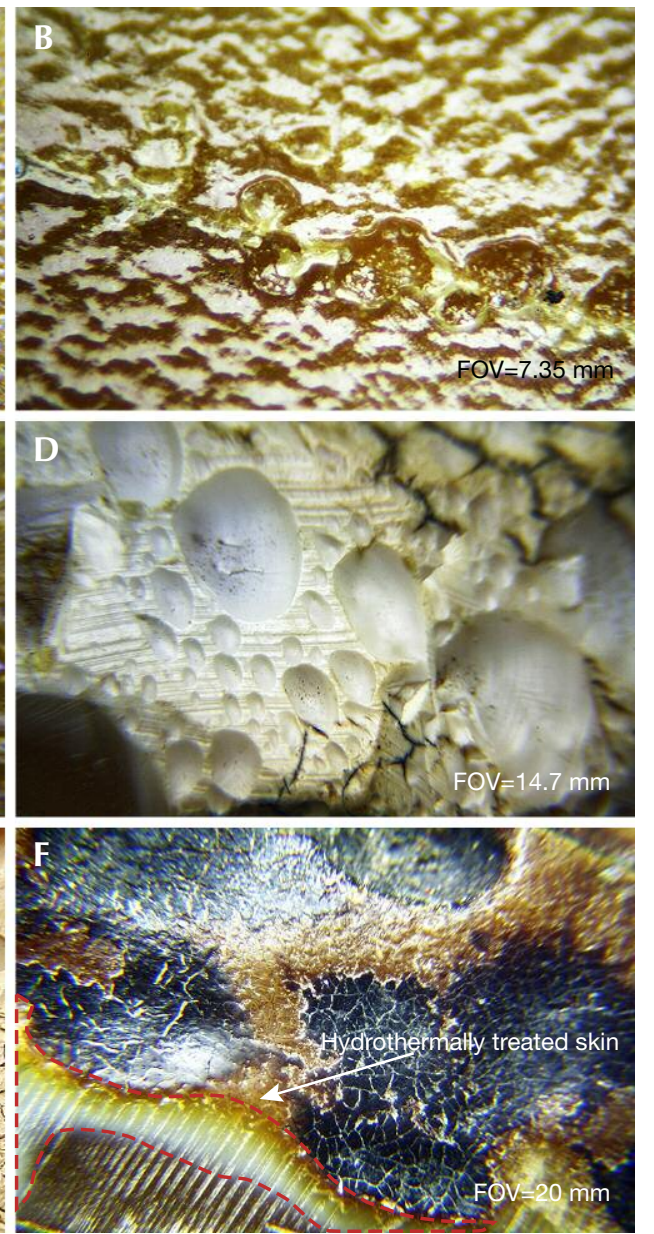

Figure 8. Features of hydrothermally treated skin. A and B: water ripple structure. $C$ and $D$ : oriented and distributed bubbles or residual porosity on $\mathrm{HT}$ skin. E: cracked or brown crust-like HT skin. F: yellowish white HT skin below the weathered skin of rough amber material. These previously examined samples were collected from amber manufacturing facilities. Photos by Yamei Wang. 

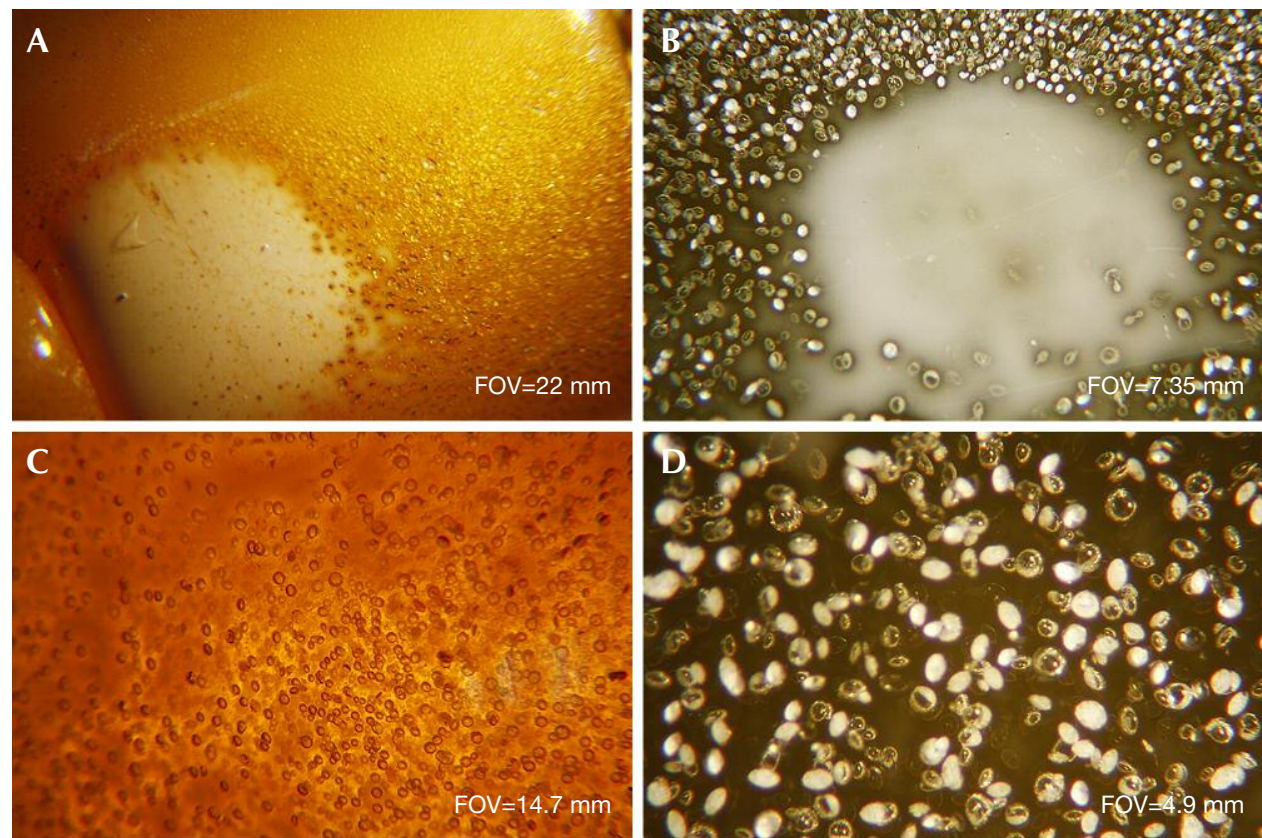

Figure 9. Inclusions in HT amber. A: HT spots on the surface of roasted HT amber. B: HT spots on finished amber surface. C: dense, flat gas
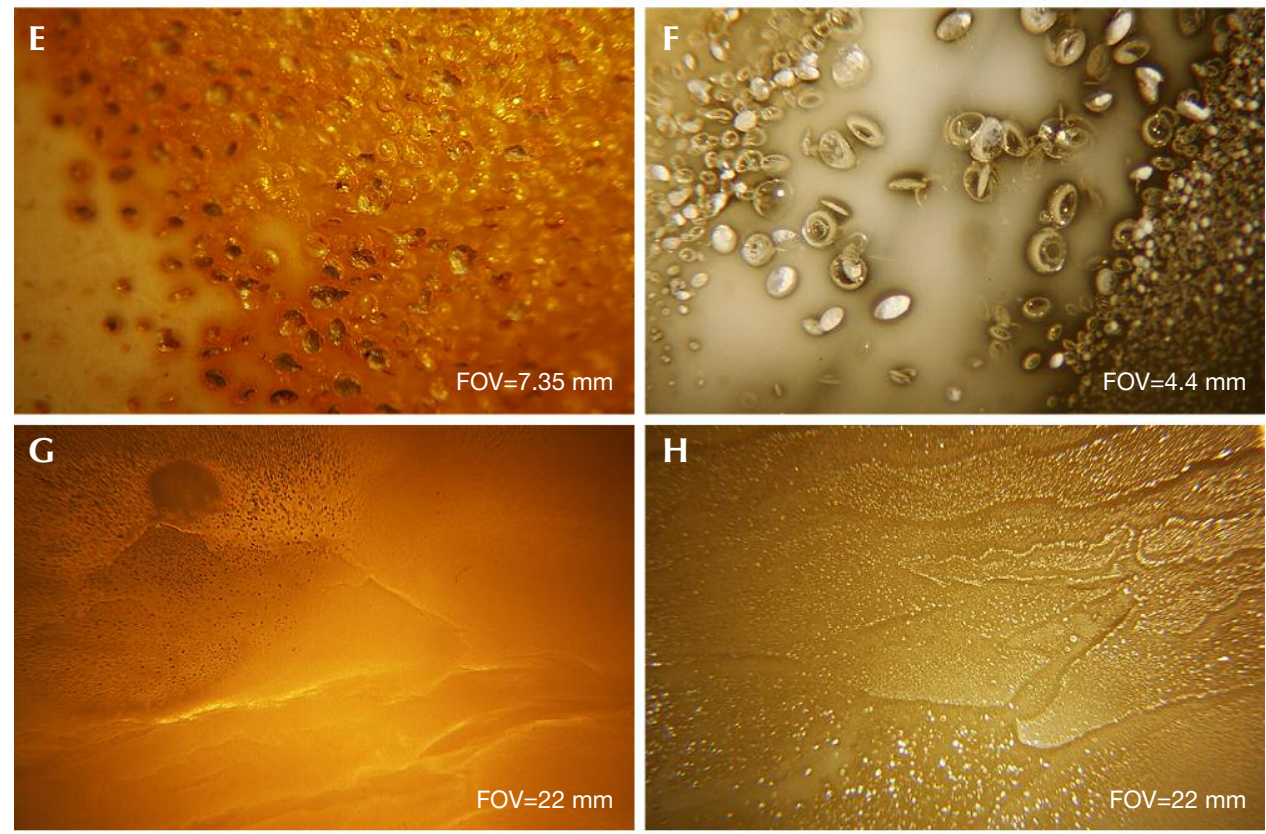
bubbles. D: dense, diskshaped gas inclusions. E: bubble cluster near the HT spots. F: enriched gas-liquid phase inclusions. G: fuzzy flow lines. $H$ : disordered flow lines. I: color zoning close to the surface of roasted HT amber. I: a spread white pattern along the crack. These previously examined samples were collected from amber manufacturing facilities. Photos by Yamei Wang.
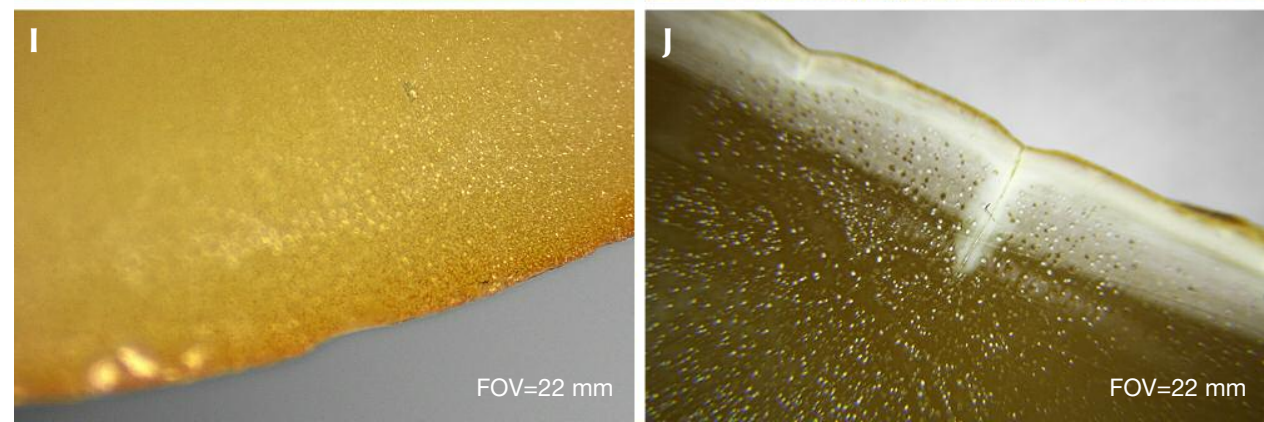

ference if the sample is not roasted but only hydrothermally treated. A white diffusion pattern ap- pears along the cracks after hydrothermal treatment of originally cracked amber (figure 9J). 

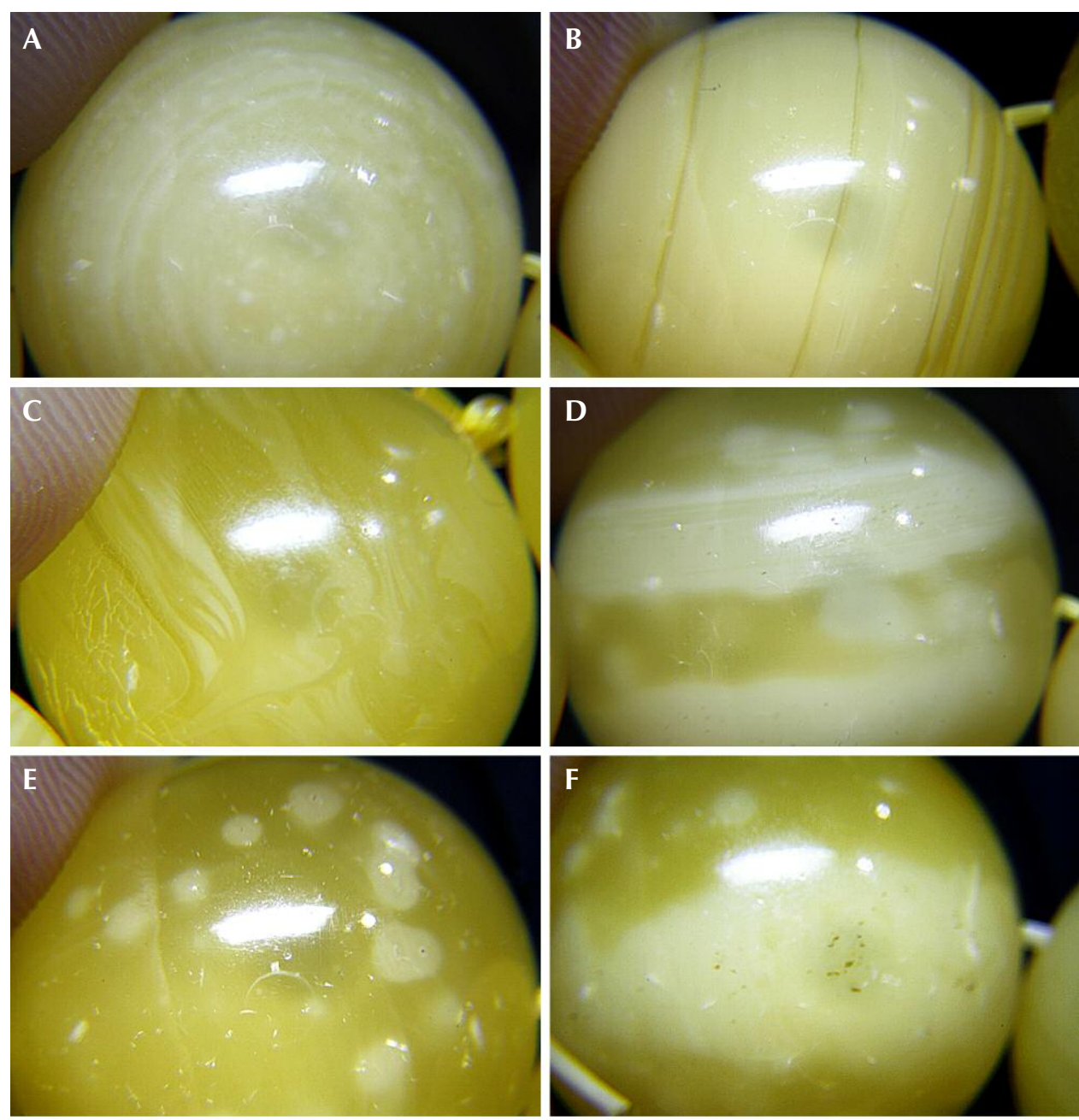

Figure 10. A: concentric structures of HT copal beads. B: thick and thin straight lines of HT copal beads. C: flow lines similar to beeswax. D: striped structures of HT copal beads. E: round dot-like HT spots. F: large HT spots. G: densely distributed HT spots along the white belt. H: obvious boundaries between the opaque and transparent areas (the diameter of the bead is around 11-12 $\mathrm{mm}$ ). These previously examined samples were from a client's collection. Photos by Yamei Wang.
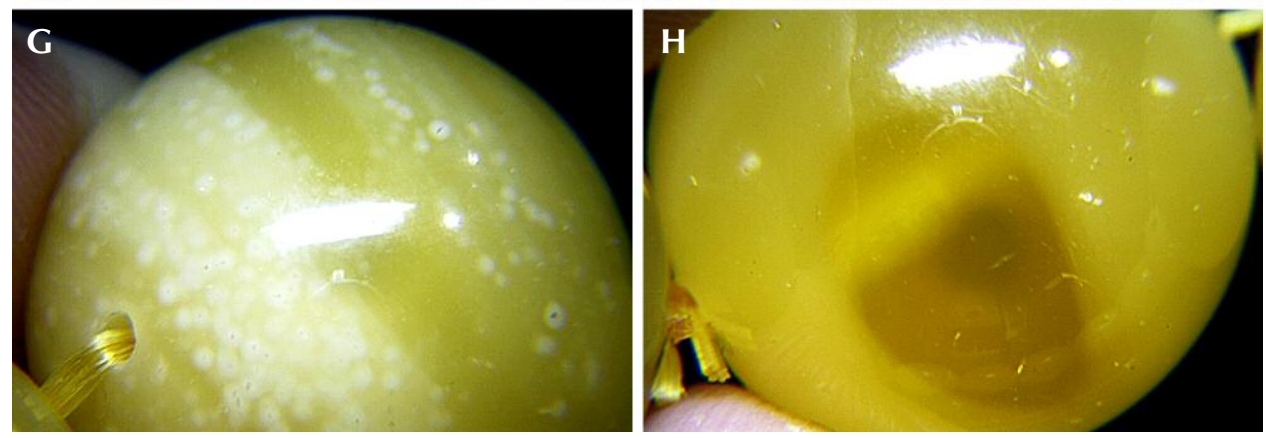

Microscopic Characteristics of Hydrothermally Treated Copal Resin. The HT copal resin finished products (figure 10) mimic the appearance of natural beeswax. For example, Colombian copal resin can be transformed into yellow or yellow-green opaque copal after hydrothermal treatment. The client who sent the copal resin beads for examination acknowledged that they went through multiple cycles of hydrothermal treatment, around 20 hours total. Since the original copal resin material is transparent with- out flow lines, the HT copal will not show the flow patterns. This is very different from HT amber, which often starts with gold-twisted honey amber full of flow lines. These flow lines are often retained in the HT products. HT copal resin instead shows more concentric rings and a straight, irregular, and banded or striped texture (figure 10, A-D). There are various forms of HT spots (figure 10, E-G), and the boundaries between the opaque and transparent areas of copal are often very obvious (figure $10 \mathrm{H}$ ). There 

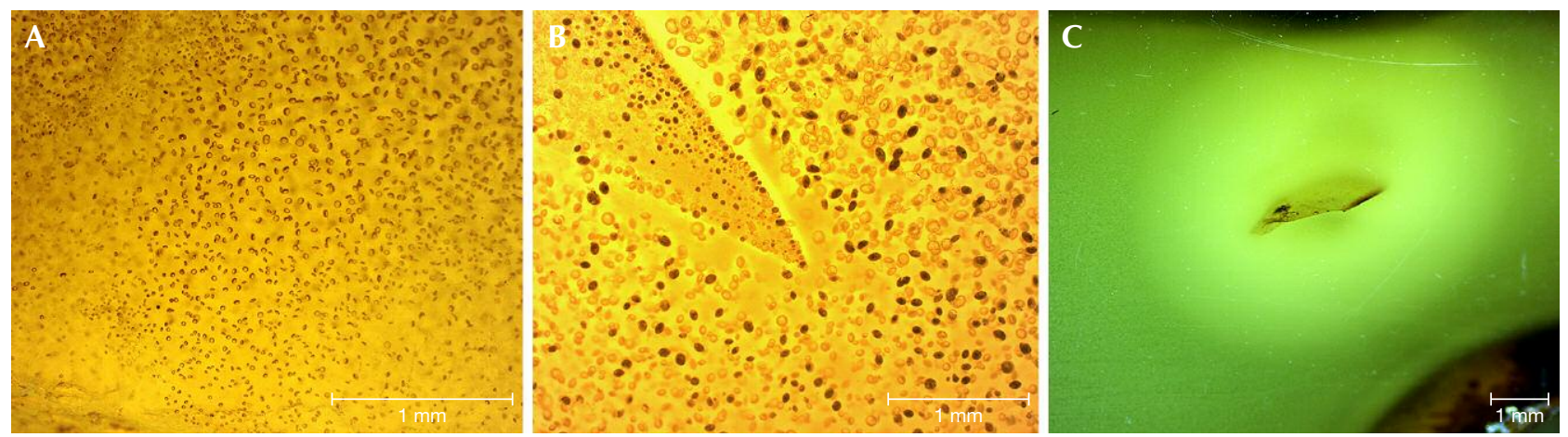

Figure 11. A and B: Disk-like bubbles in HT copal resin. C: Large HT spots on the surface of a copal resin sample. These samples were from a client's collection. Photos by Yamei Wang.

are obvious disk-like bubbles in the HT copal resin and large HT spot residues on the surface of copal resin (figure 11).

\section{DISCUSSION}

The Mechanism of Hydrothermal Treatment. The purpose of hydrothermal treatment is to generate the same mechanism that turns natural beeswax opaque by adjusting the temperature, pressure (inert gas), and saturated vapor pressure inside the furnace to make the water vapor penetrate the softened amber. To better illustrate the equilibrium of two-phase wet steam on the amber surface, the hydrothermal treatment process is illustrated in figure 12A. The effect is sim- ilar to when a tap water valve is opened all the way and the high water pressure in the pipe causes bubbles to form as air is trapped within the water, making it appear white and opaque. When the water pressure is reduced close to atmospheric pressure, the flowing water does not contain so many air bubbles and becomes transparent (figure 12B, top).

There are two types of vaporization: evaporation and boiling. Evaporation occurs on the surface, while boiling occurs when the saturated vapor pressure is equal to the external pressure. Both forms are suitable for hydrothermal treatment of amber. First of all, amber in the furnace will be affected by the dual role of temperature and pressure, resulting in softening

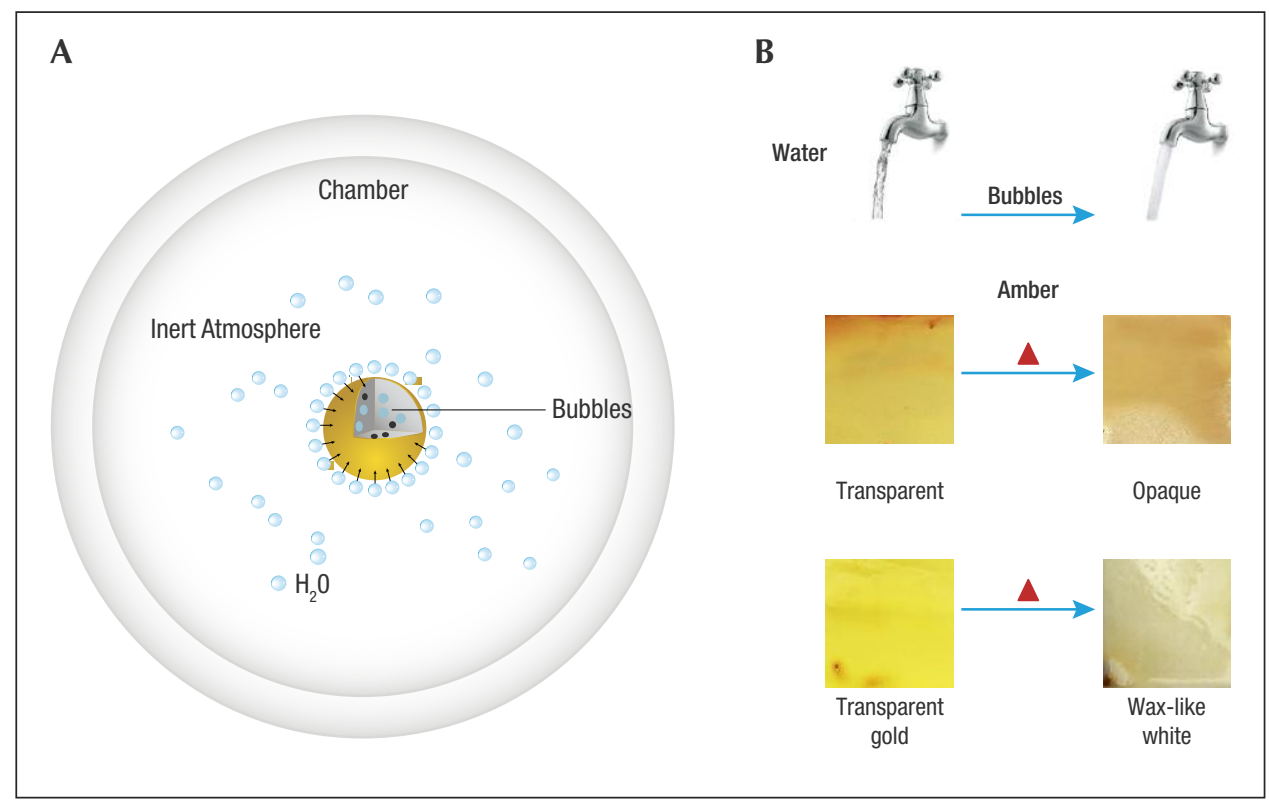

Figure 12. A: Evaporation of $\mathrm{H}_{2} \mathrm{O}$ steam on amber in the chamber under inert atmosphere. B: Hydrothermal treatment introduces tiny bubbles into transparent amber the red triangle represents hydrothermal treatment). Illustrations by Yan Li. 

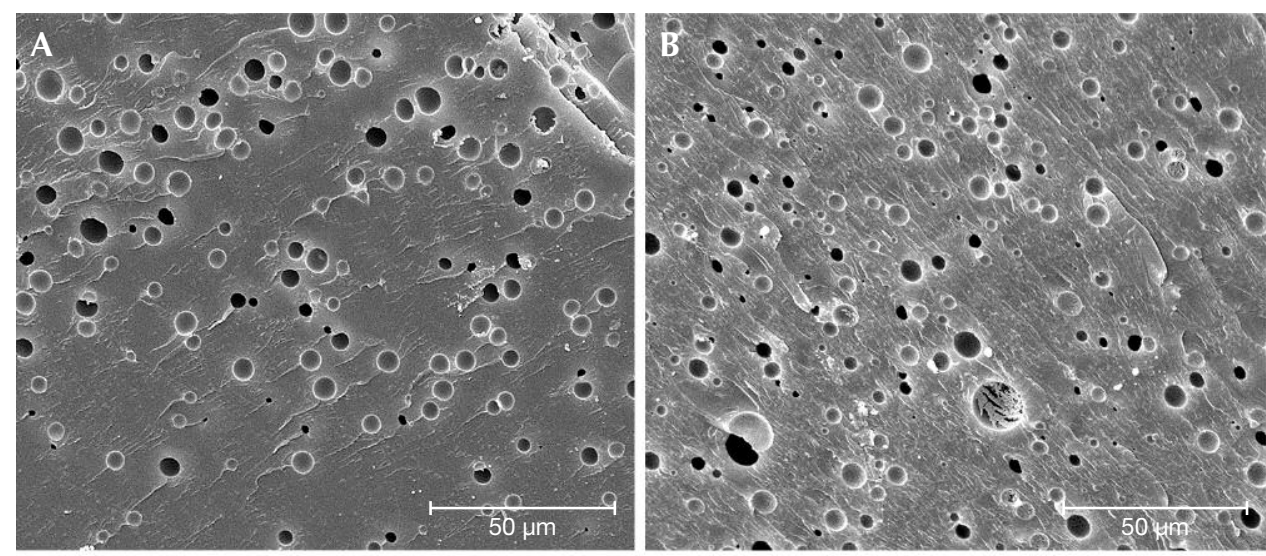

Figure 13. SEM images of bubbles in $(A)$ natural beeswax and (B) HT beeswax amber. SEM images of $(C)$ natural white beeswax and $(D)$
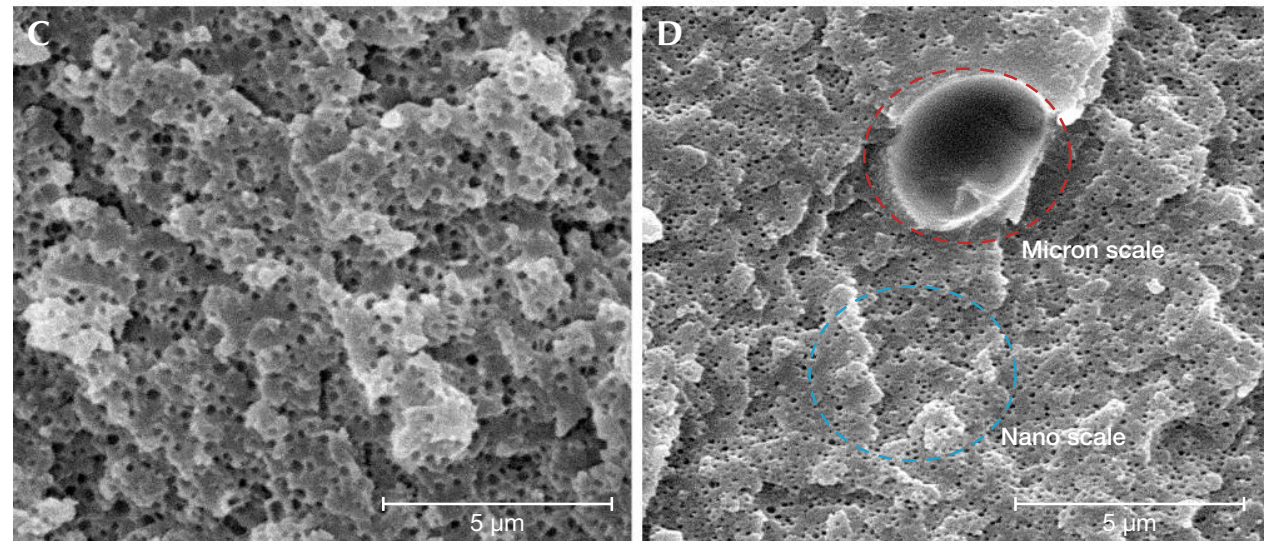
crust of HT white beeswax. Samples were collected from amber manufacturing facilities. Photos by Yamei Wang.

(making it rubbery). Meanwhile, at a certain temperature when the conditions in the chamber are adequate to give the water molecules enough kinetic energy to break away from the surrounding molecules, steam will form. Water vapor in the chamber by means of steam pressure and the pressure of external inert gas constantly penetrates the softened amber in the form of wrapped bubbles; the amber becomes opaque, with a wax-like or milky color, achieving the appearance of beeswax.

Beeswax is translucent to opaque and milky in appearance, the result of reflection and scattering of light by abundant tiny gas bubbles in the amber. Wang et al. (2016) used SEM to observe the size and distribution of bubbles per unit area and the area ratio of bubbles in a variety of amber specimens. The gas bubbles, caused by the volatile materials within amber, have a round shape (ranging from $100 \mathrm{~nm}$ to $15 \mu \mathrm{m}$, with a density of hundreds to thousands of bubbles per $\mathrm{mm}^{2}$ ) and are uniformly distributed. The density of the gas bubbles is positively related to the amber's opacity. The higher density of the gas bubbles leads to a less transparent appearance. The smaller the gas bubbles, the smoother or more compact the texture is.
HT Amber Quality and Durability. Softening the amber is a prerequisite of treatment. Once softened, the amount of gas bubbles penetrating the amber during hydrothermal treatment is related to pressure. There is no obvious difference in the size range of gas bubbles in natural beeswax and HT beeswax under SEM because of the much smaller area of observation (figure 13, A-B). However, the observation is dramatically different under an optical microscope: The gas bubbles in HT beeswax are small and flattened or disk-shaped and densely distributed (figure 9D). Gas bubbles in natural white beeswax can only be observed under SEM of 5000-10,000× magnification. In general, $30 \times$ or higher magnification is required to see bubbles in natural beeswax, while 10× magnification is sufficient for HT amber. The white HT skin is caused by rapid accumulation of tiny gas bubbles in the highly porous shallow surface of the amber. Gas bubbles can be divided into two different groups: the micron-scale bubbles that are clearly visible at $800 \times$ magnification (figure $13 \mathrm{~B}$ and $13 \mathrm{D}$, red circle) and the secondary nano-scale bubbles visible at $10,000 \times$ magnification (figure 13D, blue circle). The density of bubbles in beeswax is positively related to opacity. Both the porcelain white color and the com- 

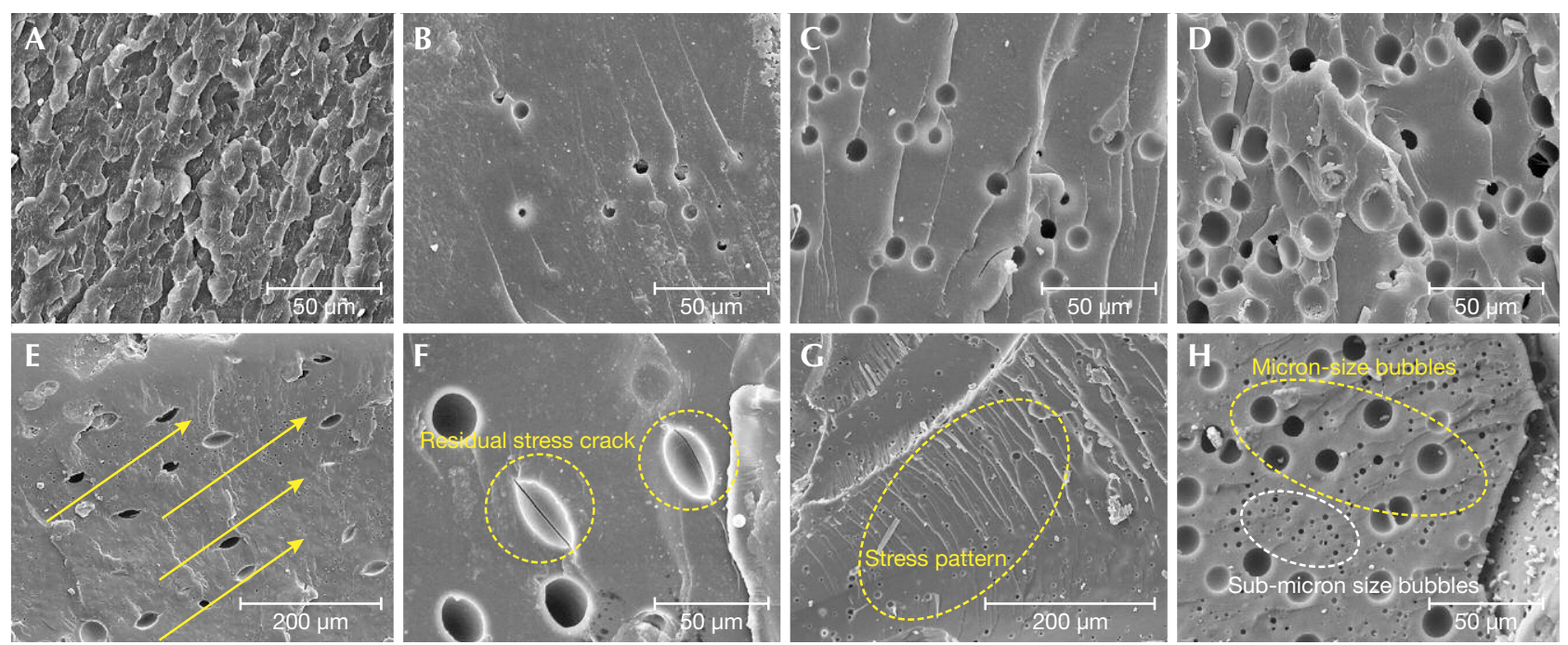

Figure 14. SEM images $A-D$ show the characteristics of natural beeswax. A: layering structure. B: gas bubbles scattered in the amber matrix. C: gas bubbles with a size of 8-11 $\mu \mathrm{m}$, uniformly dispersed in the matrix. D: closely distributed gas bubbles, 8-17 $\mathrm{mm}$. SEM images E-H show the characteristics of hydrothermally treated beeswax. E: oval bubbles oriented along the long axis. F: residual stress cracks along the oval bubbles. G: a parallel stress pattern. H: submicron-/micron-sized bubbles. These previously examined samples were collected from amber manufacturing facilities. Photos by Yan Li.

pact structure of high-quality natural white beeswax are attributed to the nano-scale bubbles (figure 13C). Hence, the large amount of artificially introduced nano-scale bubbles (figure 13D, blue circle) in the treated samples will lead to an even more compact structure of white HT skin and a milky appearance.

HT beeswax beads are especially prone to breaking or cracking in the process of drilling. In comparison, natural beeswax has high toughness, possibly due to its layering structure (figure 14A). The distribution, amount, and density of tiny gas bubbles in the HT amber was different from that in natural beeswax (figure 14, B-D). Depending on the cutting direction, it is possible to see both circular and oval bubbles in HT amber, and figure 14E shows an orientation along the bubbles' long axis direction and residual stress cracks along the oval bubbles (figure 14F), accompanied by small but obvious stress patterns (figure 14G). HT beeswax is easily burst during processing due to residual stress cracks. The submicron-/micron-sized bubbles (figure 14H) penetrating the HT amber are associated with a certain pressure that has not been disclosed. It is presumed that gas bubbles form in HT beeswax from the synergistic effect of temperature and pressure during the hydrothermal treatment process. Adjacent gas bubbles may squeeze each other, resulting in deformation and forming stress patterns or lines.
Definition and Identification of Hydrothermally Treated Amber. Definition and Naming. Since HT amber is a new product, the authors suggest that several factors be taken into consideration for defining it:

1. The hydrothermal treatment process is similar to heat treatment in practice, as both are completed in a pressure furnace. They have opposite outcomes, however (Wang et al., 2010). Heat treatment is a purification process for squeezing gas inclusions out of the amber to form transparent golden amber, while hydrothermal treatment aims to introduce submicron-/micron-sized bubbles into the amber to create a milky appearance (figure 15).

2. Hydrothermal treatment aims to improve the appearance of amber by artificially creating inclusions, causing the appearance of natural beeswax. Translucent amber, semi-beeswax, gold-twisted honey amber, transparent gold amber, and low-quality beeswax usually serve as the starting materials for hydrothermal treatment.

3. HT amber (figure 16, left) is mostly used for further heat treatment to produce roasted old beeswax (figure 16, right; see definition in box 

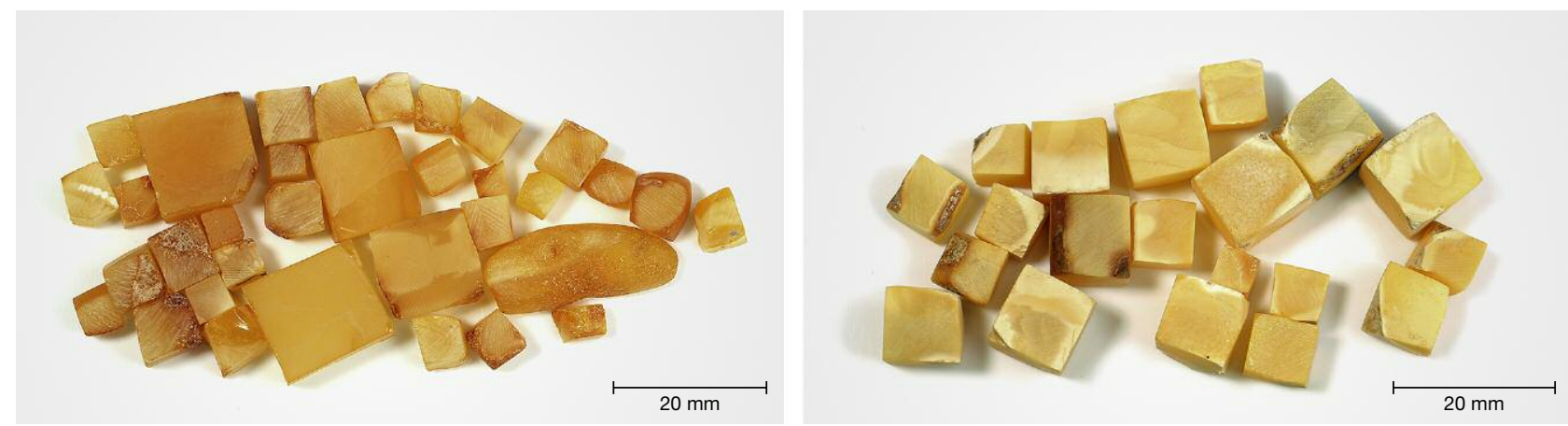

Figure 15. Semi-finished amber before and after hydrothermal treatment, photographed at the factory. Photos by Yamei Wang.

A). Natural beeswax with a faint yellow color could be heat-treated to mimic saturated yellow or dark yellow beeswax (see figure A-2C). The roasted old beeswax formed slowly due to oxidation from more than 15 days of continuous heat treatment at $60-90^{\circ} \mathrm{C}$ under atmospheric pressure (figure 1, D-F). However, the structure of the roasted HT amber did not change significantly, indicating its durability.

4. HT amber is mainly composed of foreign gas bubbles in the structure through physical introduction, but natural beeswax contains its own volatile ingredients (Yang et al., 2002). A series of processes take place during the formation of amber from resinite. Two key processes have been recognized by researchers, namely polymerization and volatilization (Scalarone et al., 2003; Guiliano et al., 2007). Volatilization refers to the process in which volatile components (VCs) contained in the original resinite continuously escape during the geological process. The VCs mainly include terpenes, unsaturated compounds, and carboxylic acids (Matuszewska and John, 2004). According to the shape and distribution of bubbles in amber, it is speculated that the formation of bubbles is related to terpenes, succinic acid, and other volatiles carried by amber itself. This is distinctly different from gas- liquid inclusions, which are isolated, gas-liquid two-phase inclusions (figure 9F, observed by gemological microscope).

Baltic amber comes from pine and cypress trees. Infrared spectroscopy shows that it has a higher content of volatile components and succinic acid in the initial resinite than amber from other areas (such as Myanmar, Mexico, China, and the Dominican Republic). FTIR results show that almost all Baltic amber without heat treatment has a set of absorption peaks near 3070,1645 , and $888 \mathrm{~cm}^{-1}$ caused by $\mathrm{C}=\mathrm{C}$ stretching vibration and out-of-plane bending vibration of $\mathrm{C}-\mathrm{H}$ on the double bond of methylene outside the ring (Wang et al., 2016). These absorption peaks reflect the fact that while the evolution of Baltic amber took place over a period of 50 million years, a small amount of volatile terpenes containing unsaturated bonds remained. The VCs were buried together with the resinite, leading to the change in shape and distribution of bubbles with the variations of temperature, pressure, wall rock type, and other geological conditions. Since the Tertiary period, the geological conditions of the Baltic Sea area have continuously evolved. The volatile components of buried resin fossils have continuously escaped over that time. However, amber can be found in geological environments with high pressure (for example, the surrounding rock of amber in the Baltic Sea was
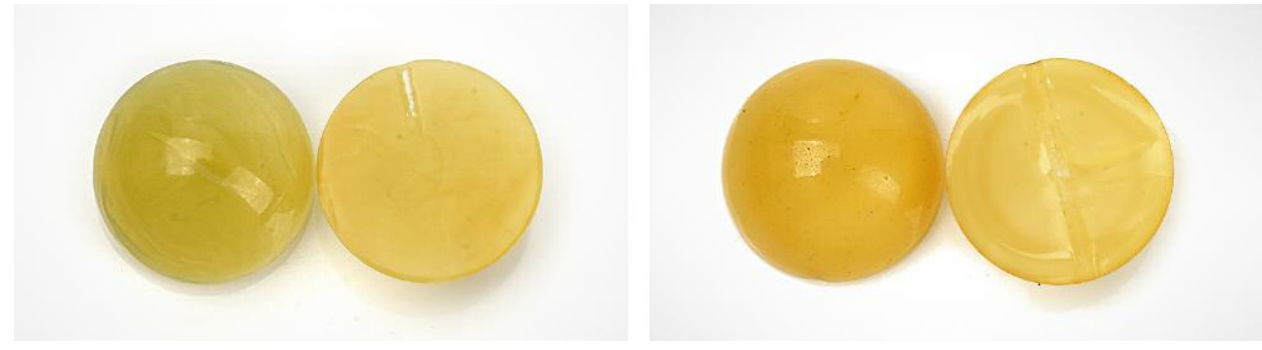

Figure 16. Left: HT amber beads. Right: The roasted HT amber with enhanced color. Samples were collected from the factory. Photos by Yamei Wang. 


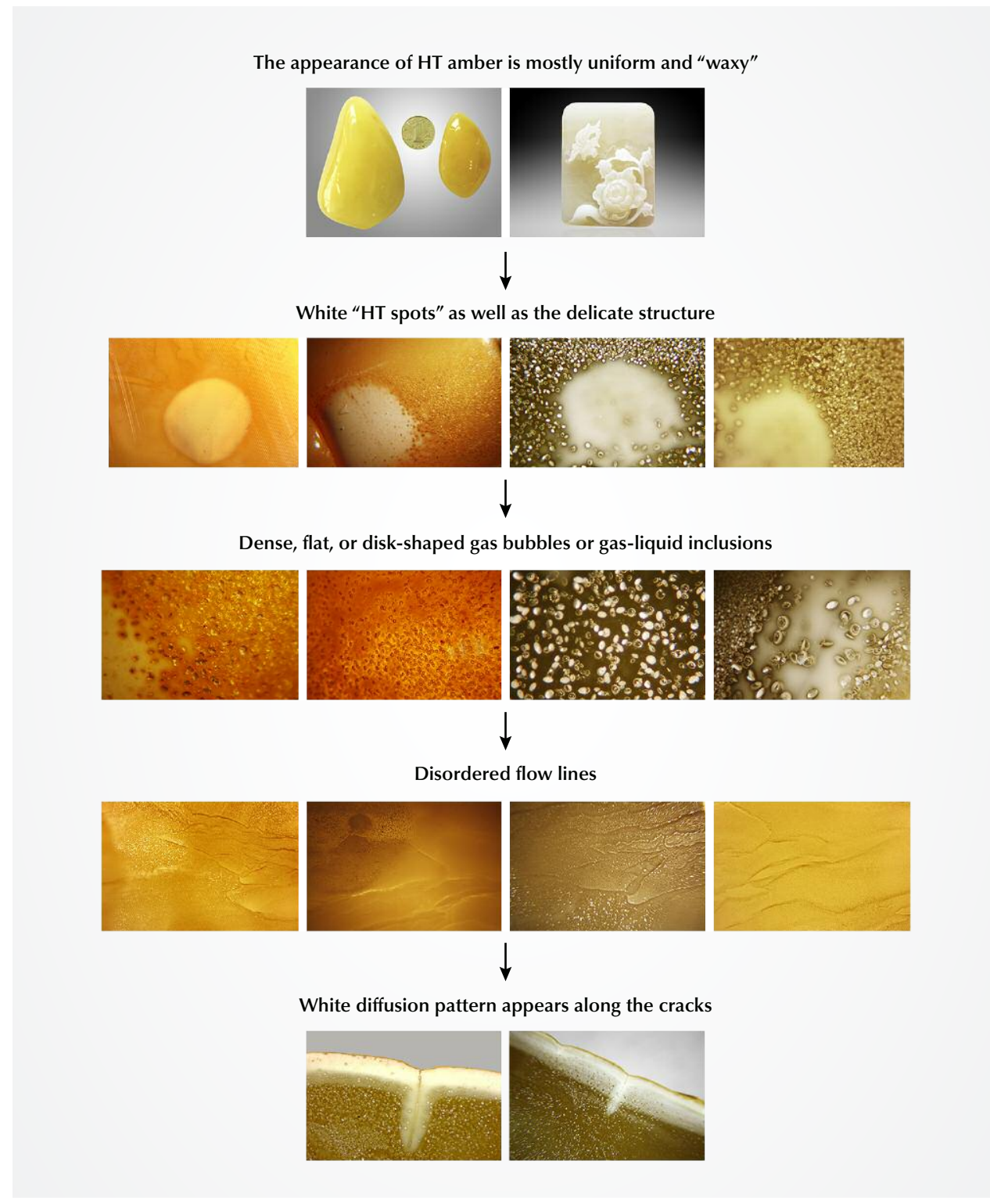

Figure 17. Flowchart for the identification of hydrothermally treated amber. Photos by Yamei Wang.

mainly a blue mud layer). Occasionally bubbles are enclosed in amber to form beeswax, and they tend to become smaller. Gas chromatography coupled with mass spectrometry has been successfully used for identification of VCs contained in the fossil resin matrix (Stout et al., 2000; Vîrgolici et al., 2010), and the results confirmed that the VCs mainly consist of aromatic compounds such as terpenes, semiquinones, and biguanides.

The authors believe that hydrothermal treatment is a practical and acceptable method to enhance the appearance of amber to fulfill market demand in certain locations. Western markets might not enjoy the opaque products as much as the Chinese market. This belief is based on a comprehensive analysis of the nature of the HT treatment materials, technical process, purpose, effect, stability, market acceptance, and detection standards. In recent years, it has been used more and more widely in the market and accounts for a relatively large proportion of bead products. In order to ensure that consumers are informed, it should be referred to as amber rather than beeswax. However, the use of hydrothermal treatment needs to be disclosed.

Identification of Hydrothermally Treated Amber. As explained above, it is feasible for experienced gemologists to definitively identify HT amber pieces. Identification focuses on external and internal characteristics (figure 17): 
1. The appearance of HT amber is mostly uniform and waxy.

2. It sometimes displays white HT spots as well as a compact structure.

3. There are usually dense, flat, or disk-shaped gas bubbles or gas-liquid inclusions in HT amber. Also, the gas bubbles in HT amber are generally much larger than those in natural beeswax.

4. HT amber retains the natural flow lines of goldtwisted honey amber. However, the flow lines appear disordered, less well-defined and smooth than the pattern of natural beeswax, which may be attributed to the impact of later gas interventions.

5. A white diffusion pattern appears along cracks after treatment of original cracked amber.

\section{CONCLUSIONS}

Hydrothermal treatment can be used to improve the appearance of amber materials (from transparent to opaque) to cater to Chinese consumers. During the process, an abundance of tiny submicron-/micronsized bubbles penetrate the amber in an aqueous solution (with some catalyst) through controlling the temperature and pressure and selecting an inert atmosphere environment. After treatment, the inner layer of the weathered skin of rough amber material will generate a layer of yellowish white or greenish yellow HT skin of various thicknesses, or a corrugated crust containing pores. The finished amber shows a residue of hydrothermally treated spots of different sizes, which may penetrate the amber's interior or remain on the polished surface. It is recommended to look for dense, flat, or disk-shaped bubbles and gas-liquid inclusions in the finished products. In addition, the original flow pattern in the gold-twisted honey amber affected by the subsequent interference of tiny bubbles appears disorderly, unclear, and less smooth. Because the infrared spectra data of the experimental samples before and after the treatment showed little difference, FTIR spectra cannot be considered conclusive (though they do facilitate the identification). A series of careful observations and tests are needed to identify HT amber.
ABOUT THE AUTHORS

Ms. Wang is an associate professor at the Gemological Institute, China University of Geosciences in Wuhan, and the director of the university's gem testing center in Guangzhou. Dr. Li (yanli@cug.edu.cn, corresponding author) is an associate professor at the Gemological Institute and Advanced Manufacturing Centre, China University of Geosciences in Wuhan. Ms. Fen Liu and Ms. Fangli Liu are gemologists in the Gem Testing Center, China University of Geosciences in Wuhan. Dr. Chen is an associate professor at the Gemological Institute, China University of Geosciences in Wuhan.

\section{ACKNOWLEDGMENTS}

The authors thank all the parties who have contributed to the project, especially the anonymous companies for their great support and fruitful discussions. The thoughtful and constructive comments by reviewers and technical editors are gratefully acknowledged. This research was financially supported by Grant No. 2018 YFF0215403 from the National Key R\&D Program of China. The project was partially supported by the Fundamental Research Funds for the Central Universities, China University of Geosciences (Wuhan) (No. CUG170677).

\section{REFERENCES}

Abduriyim A., Kimura H., Yokoyama Y., Nakazono H., Wakatsuki M., Shimizu T., Tansho M., Ohki S. (2009) Characterization of "green amber" with infrared and nuclear magnetic resonance spectroscopy. Ge G, Vol. 45, No. 3, pp. 159-171, http://dx.doi.org/10.5741/GEMS.45.3.158

Brody R.H., Edwards H.G.M., Pollard A.M. (2001) A study of amber and copal samples using FT-Raman spectroscopy. Spectrochimica Acta Part A: Molecular and Biomolecular Spectroscopy, Vol. 57, No. 6, pp. 1325-1338, http://dx.doi.org/ 10.1016/S1386-1425(01)00387-0
Feist M., Lamprecht I., Müller F. (2007) Thermal investigations of amber and copal. Thermochimica Acta, Vol. 458, No. 1-2, pp. 162-170, http://dx.doi.org/10.1016/j.tca.2007.01.029

Guiliano M., Asia L., Onoratini G., Mille G. (2007) Applications of diamond crystal ATR FTIR spectroscopy to the characterization of ambers. Spectrochimica Acta Part A: Molecular and Biomolecular Spectroscopy, Vol. 67, No. 5, pp. 1407-1411, http://dx.doi.org/10.1016/j.saa.2006.10.033

Matuszewska A., John A. (2004) Some possibilities of thin layer chromatographic analysis of the molecular phase of Baltic 
amber and other natural resins. Acta Chromatographica, No. 14, pp. 82-91.

Ross A. (2010) Amber: The Natural Time Capsule. Firefly Books Ltd., Ontario, Canada.

Scalarone D., Lazzari M., Chiantore O. (2003) Ageing behaviour and analytical pyrolysis characterisation of diterpenic resins used as art materials: Manila copal and sandarac. Journal of Analytical and Applied Pyrolysis, Vol. 68-69, pp. 115-136, http://dx.doi.org/10.1016/S0165-2370/03)00005-6

Stout E.C., Beck C.W., Anderson K.B. (2000) Identification of rumanite (Romanian amber) as thermally altered succinite (Baltic amber). Physics and Chemistry of Minerals, Vol. 27, No. 9, pp. 665-678, http://dx.doi.org/10.1007/s002690000111

Vîrgolici M., Ponta C., Manea M., Negut D., Cutrubinis M., Moise I., Suvaila R., Teodor E., Sarbu C., Medvedovici A. (2010) Thermal desorption/gas chromatography/mass spectrometry approach for characterization of the volatile fraction from amber specimens: A possibility of tracking geological origins. Journal of Chromatography A, Vol. 1217, No. 12, pp. 1977-1987, http://dx.doi.org/10.1016/i.chroma.2010.01.075

Wang Y., Yang Y., Yang M. (2010) Experimental study on enhancement technique of amber. Journal of Gems and Gemmology, Vol. 12, No. 1, pp. 6-11 (in Chinese with English abstract).
Wang Y., Yang M., Yang Y. (2014) Experimental studies on the heat treatment of Baltic amber. GÆG, Vol. 50, No. 2, pp. 142-150, http://dx.doi.org/10.5741/GEMS.50.2.142

Wang Y., Wang Q.Y, Nie S. (2016) Gas bubble characteristic of translucent to opaque amber and its relationship to quality assessment. Journal of Gems and Gemmology, Vol. 18, No. 5 , pp. 20-27 (in Chinese with English abstract).

Wang Y., Yang M., Nie S., Liu F. (2017) Gemological and spectroscopic features of untreated vs. heated amber. Journal of Gemmology, Vol. 35, No. 6, pp. 530-542.

Yang J., Dong X., Guo L., Li H. (2002) The chemical research development of amber. Beijing Traditional Chinese Medicine, Vol. 21, No. 4, pp. 245-248 (in Chinese).

Yang Y., Wang Y. (2010) Summary on organic components and relevant spectral characteristics of amber and copal. Journal of Gems and Gemmology, Vol. 12, No. 1, pp. 16-22 (in Chinese with English abstract).

Zhang S.H. (2003) Can heat treatment change refractive index? Journal of Gems and Gemmology, Vol. 5, No. 2, pp. 14-15 (in Chinese with English abstract).

Zhang P.L. (2006) Systematic Gemology, 2nd ed. Geology Press, Beijing (in Chinese).

For online access to all issues of GEMS \& GEMOLOGY from 1934 to the present, visit: 